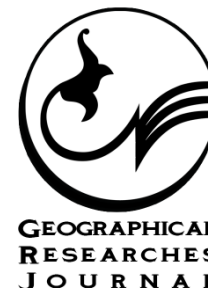

\title{
Glacial and Tectonic Evidence of Late Quaternary in Cheshmeh -Langan Basin of Isfahan
}

\section{ART ICLE INF 0}

\section{Article Type}

Original Research

\section{Authors}

Sharifi Najaf Abadi R.* PhD
How to cite this article Sharifi Najaf Abadi, R. Galcial and glacial and tectonic evidence of late quaternary in CheshmehLangan basin of Isfahan. Geographical Researches Quarterly Journal. 2018;33(2):223-237.
*Department of Basic Science, Farhangian University, Tehran, Iran

\section{*Correspondence}

Address: Department of Basic Science, Farhangian University, Tehran, Iran

Phone: -

Fax: -

Sharifi1010@gmail.com

\section{Article History}

Received: January 31, 2018

Accepted: August 6, 2018

ePublished: September 17, 2018

\section{A B S T R A C T}

Introduction and Background Quaternary is the newest life span of the planet. Contrary to the shortness of time, evidences show the diversity and significance of the events that took place.

Aims In this paper, based on the of climate and Structural geomorphology, the history of natural changes in the Cheshmeh-Langan Basin located northwest of Isfahan province during the late quaternary period has been studied.

Methodology This basin is located in central part of Zagros mountain range and Sanandaj-Sirjan zone and Zagros' fault passes from its west. In order to achieve such a goal, using available climatic data and combining it with Write method, the temperature was measured in the last glacial period and the morphology of the area was rebuilt at that time. Also, Morphological indices of active tectonic have been measured using Digital Elevation Model from topography in accuracy of $30 \mathrm{~m}$ in ARCMAP, ARC INFO, and GOLOBAL MAPER software.

Conclusion According to the evidence given, at the last Quaternary glacial phase, 72 Percent of the zone has been covered constantly with snow and ice. In such these conditions, the snow cumulated over mountainous cirques may have formed the glaciers inclined toward the foot of a mountain and U-shape valleys. These secondary glaciers have been extended after connecting each other in direction of general earth slope and directed to out of the basin. There are many valleys in this area in $\mathrm{V}$ form and not only their orientation has no correspondence with glacial directions, but also they intersect glacial directions. Studying different indices indicating dynamic tectonic and the faults of the zone reveals that after the last glacial period, the faults have been active in this zone, caused new tectonic movements. That has led to a renewal of the erosion cycle and has transformed the area into a decaying plateau. These matters are matched with Theodore Oberlander theory about Zagros stream. Accordingly, it is expected that in the future, the erosion rate in the area will still be high and tidal activities will also occur.

Keywords Fault Valleys; Quaternary Period; Mountain Glacier; Chashme-Langean Basin

\section{I T A T I O N L I N KS}

[Almodaresi \& Ramesht; 2007] The glacial effect of Shirkooh Yazd in sokhvid ...; [Bayati Khatibi; 2009] Diagnosis of neotectonic activities in the Cornucchia basin using morphotectonic and ...; [Bull; 2007] Tectonic geomorphology of mountains :A new approach to ...; [Burbank \& Anderson; 2001] Tectonic ...; [Darvishzadeh; 1991] Iranian geology ...; [Geographic organization of armed forces; 1985] Geographic organization of armed ...; [Ghahroodi Tali, et al; 2015] Estimate of snow-line in the past glacial in Dalakhani ...; [Gorabi \& Karimi; 2012] The effect of active tectonics and climate change on the evolution of the convection of Marvette, ...; [Hack; 1973] Stream-profile analysis and stream-gradient ...; [Hussein Khan Nazer; 2015] Quaternary Geology ...; [Jedari Eyvazi; 2008] Geomorphology of Iran ...; [Keller \& Pinter; 1996] Active tectonics: Earthquakes, uplift and ...; [Kyani, et al; 2016] Climate change in Gavkhouni basin at the late quaternary ...; [Maghsoudi, et al; 2016] The effect of neonate construction and climate change on the development of ...; [Mahmoodi; 1998] The rhetoric of Iran in ...; [Motammad; 1998] Tehran: Tehran University ...; [Oberlender; 2000] Zagros rivers from geomorphology view ... [Radfar \& Pourkermani; 2006] Morphotectonic of Kuhbanan ...; [Rafiei; 2009] Throat thoughts of ...; [Ramesht; 2004] The works of the fourth glaciers in the suburbs of ...; [Ramesht \& Kazemi; 2007] Glacier works in the Euclid basin of ...; [Ramesht, et al; 2011] Study of natural glacial evidences in ...; [Ramesht \& Pourdehghan; 2008] Ice in the fire: Glacier works in Bam ...; [Samari, et al; 2005] Rudbar Lorestan dam and hydro plant: Challenging ...; [Shafie Bafti, et al; 2009] Landfill and evaluation of Kuhbanan fault activity by ...; [Sharifi \& Farahbakhsh; 2015] Investigation about temperature and humidity anomalies between pleistocene and ...; [Soleimani; 1999] Guidelines for identifying active and young tectonic movements with an attitude to the preconditions of ...; [Tabasi \& Najimi; 2016] Young vertical movements in the Gareh Chay basin of Markazi ...; [Talebian \& Jackson; 2002] Offset on the main recent fault of NW Iran and implications for the late cenozoic ...; [Van Zeist \& Wright; 1963] Preliminary pollen studies at Lake Zeribar, Zagros mountains, ...; [Yamani \& Zamani; 2007] Restoration of the snow vear the border of the Shahrekord valley in the last glacial ... 


\title{
شواهد يخجالى و زمينساختى كواترنر پِين در حوضه جشمه لنتان اصفهان
}

\author{
: \\ دريافت مقاله:
}

DOI: $10.29252 /$ geores.33.2.223

جكيده

مقدمه: كواترنر جديدترين دوره عمر كره زمين است. برخلاف كوتاهى اين برهه از زمان، شواهد موجود گواه تنوع و اهميت رخخ دادهاى صورت گرفته در آن مىباشد. اهداف: در اين مقاله بر اساس آثار زئومورفولوزى اقليمى و ساختمانى تاريخ تحولات طبيعى حوضه جشمه لنكان وان واقع در شمال

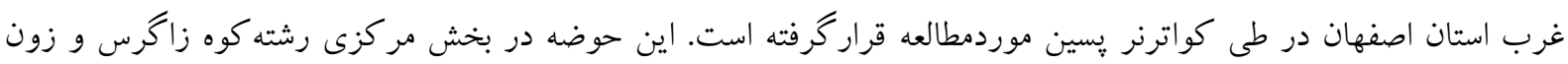

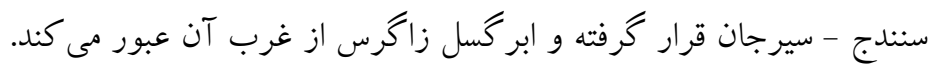

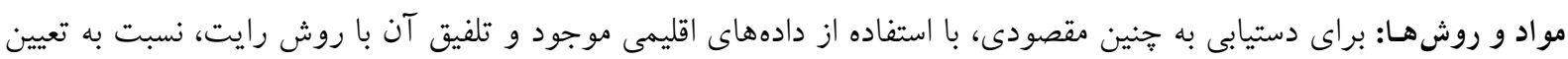

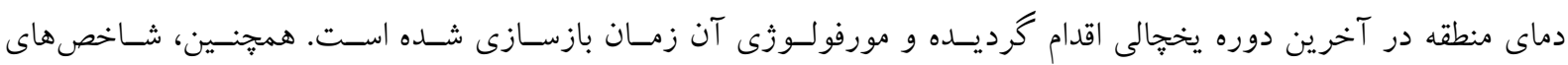

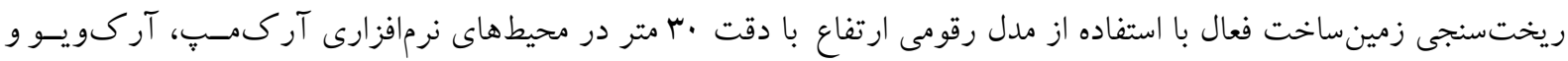
كلوبالمير اندازه گيرى شدهاند.

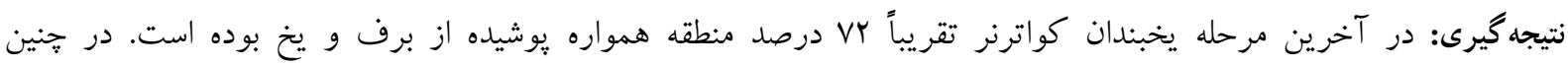

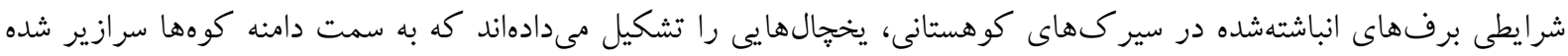

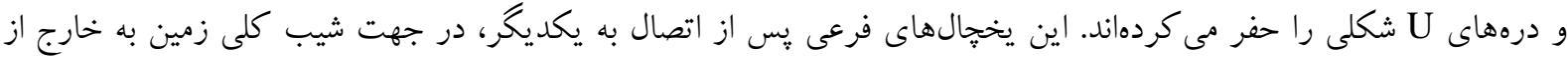

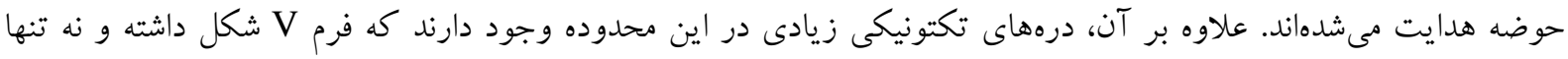

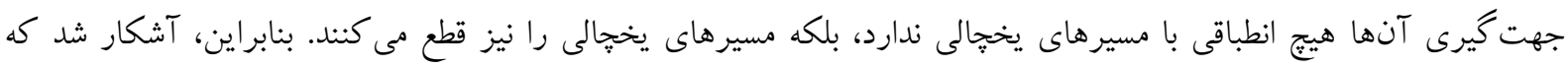

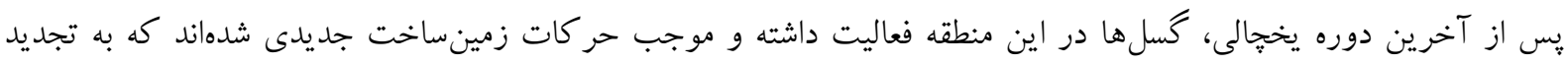

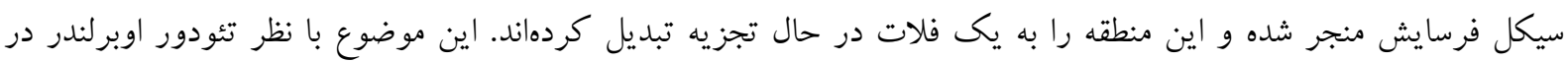

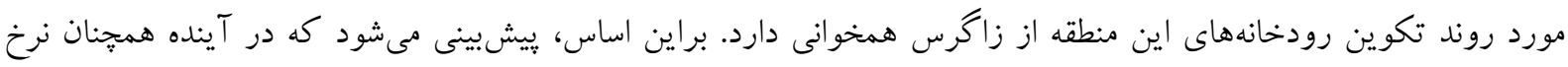

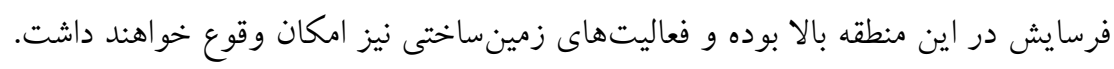
وازگ گان كليدى: درههاى گسلى، دوره كواترنر، يخجال هاى كوهستانى، حوضه جشمه لنكان

در جدول تقسيمات زمان زمينشناسى، كواترنر آخرين و كوخجىترين دوره محسوب مىشود. قبلاً حد تحتانى كواترنر بين

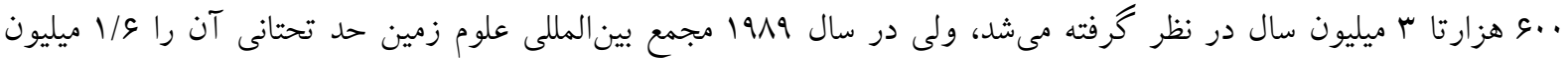

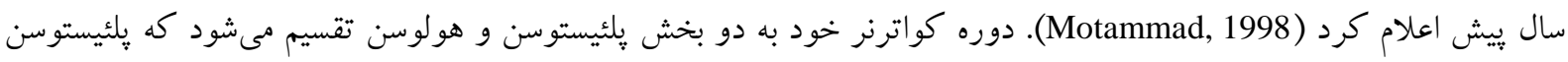




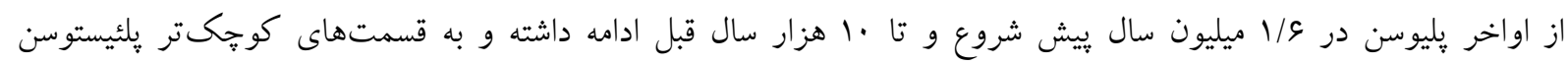
تحتانى، ميانى و وِين تقسيمشده است.

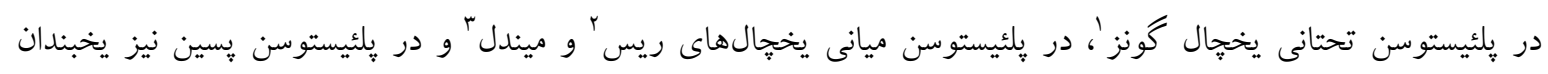

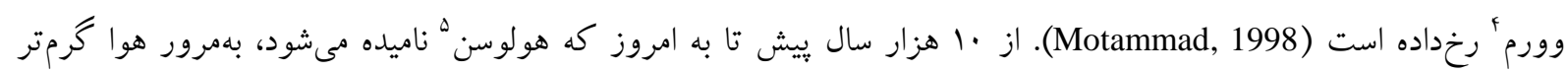

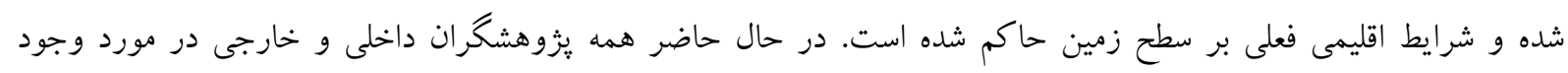

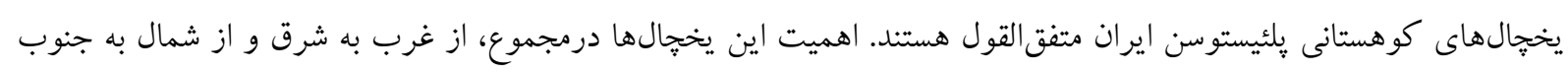

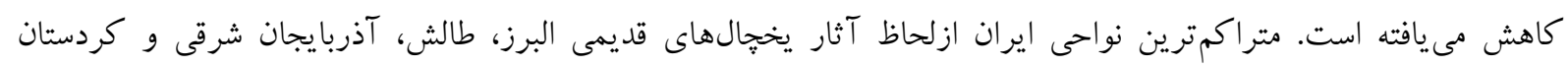

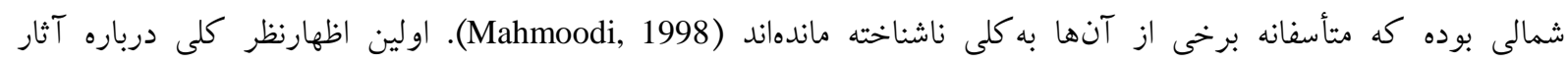

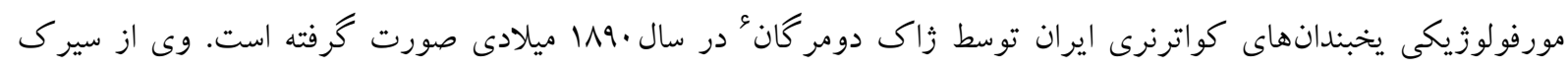

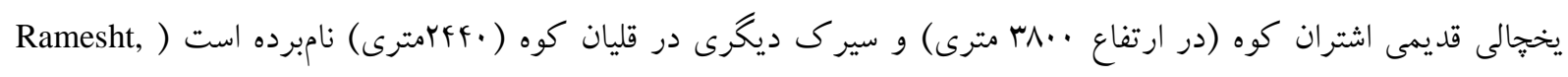

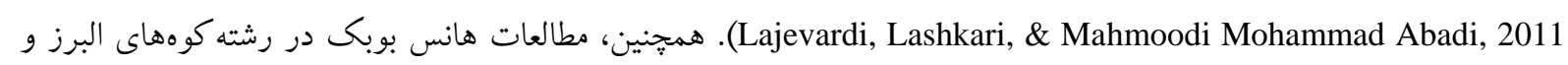

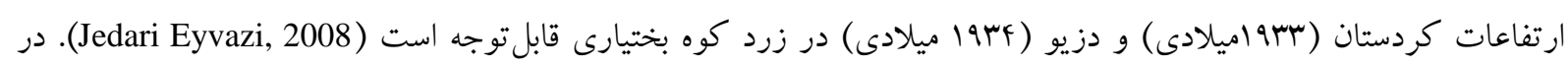

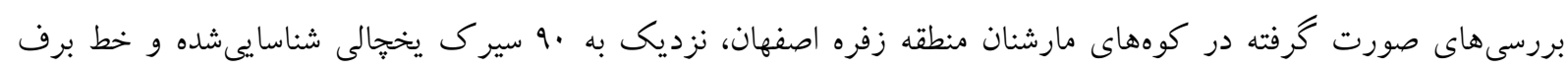

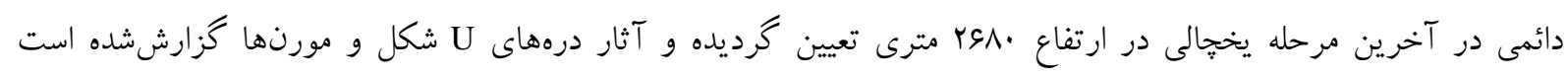

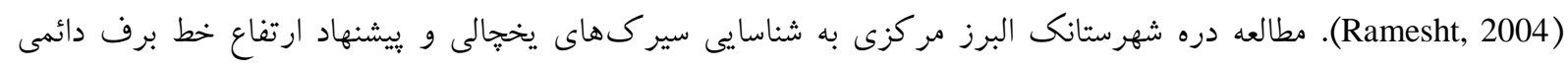

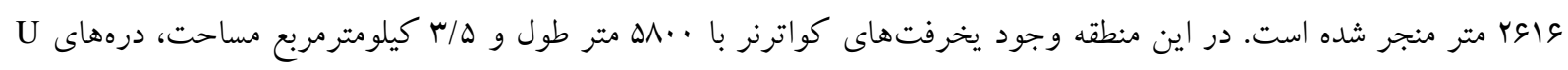

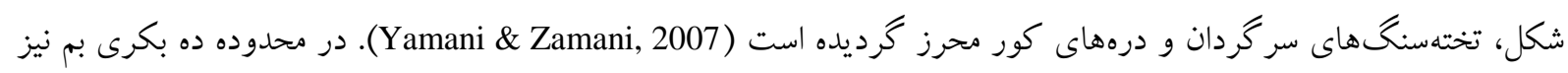

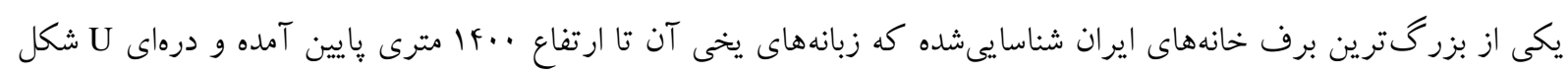
را به وجود آورده است (Ramesht \& Pourdehghan, 2008).

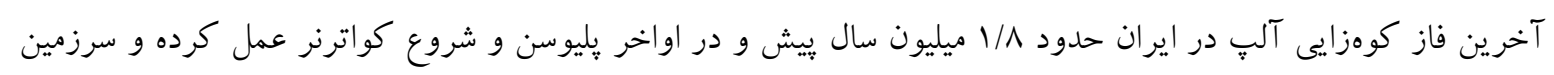

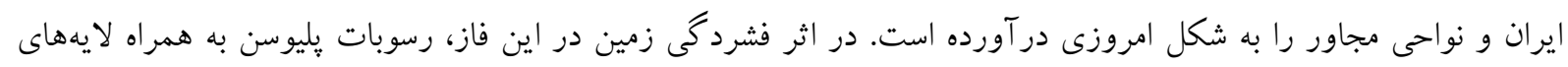

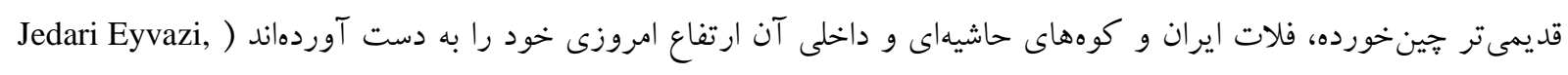

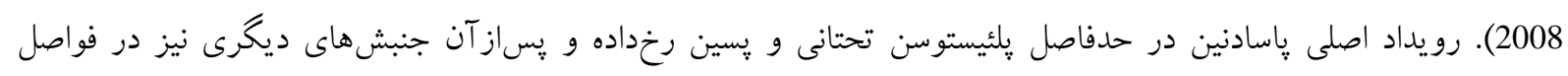

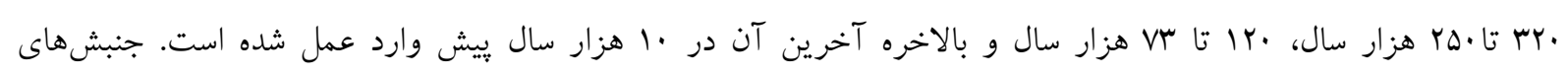

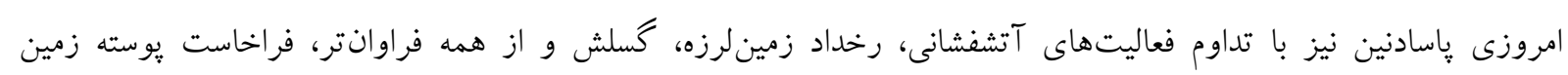

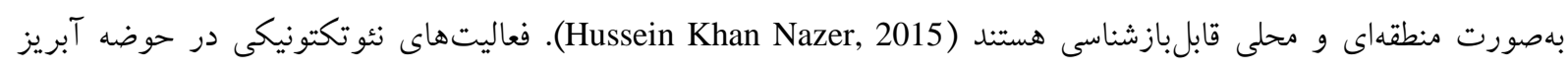

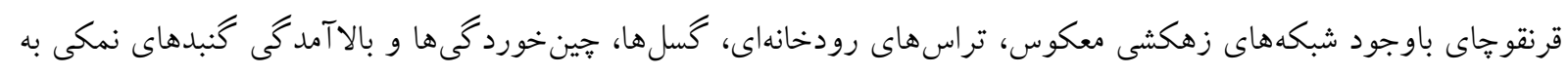

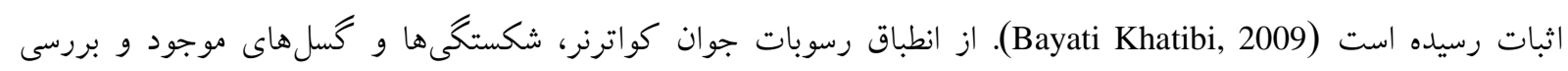

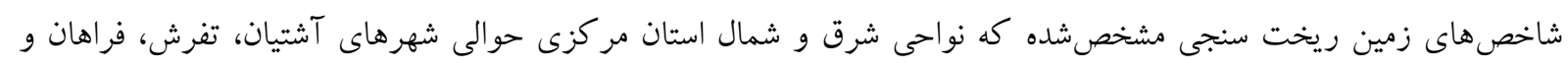

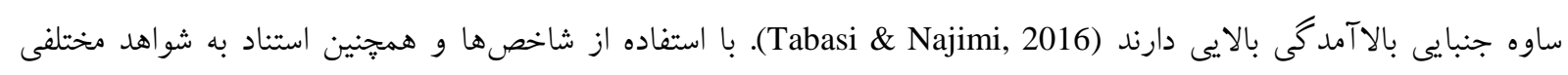

\footnotetext{
${ }^{1}$ Gunz

${ }^{2}$ Riss

${ }^{3}$ Mindel

${ }^{4}$ Wurm

5 Holocene

${ }^{6}$ De Morgan
} 


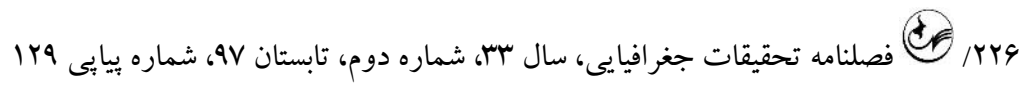

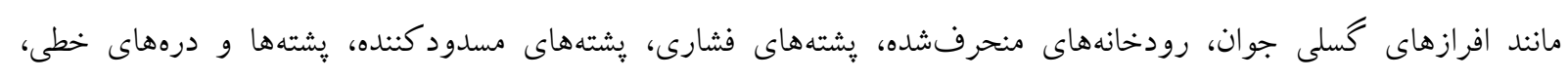

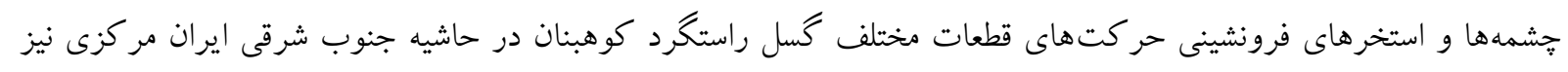

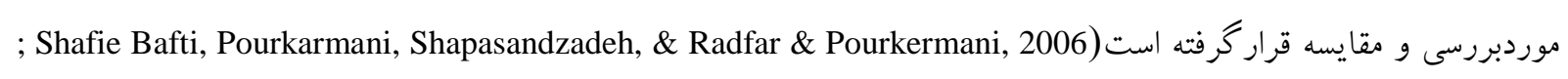

.(Iranmanesh, 2009 در برخى از ثزوهشهاى صورت گرفته تلاش شده است كه تأثيرات تغييرات اقليمى و زمينساخت فعال بر عوارض سطح

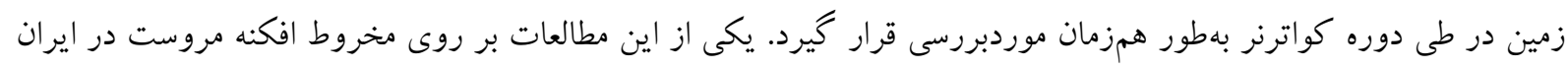

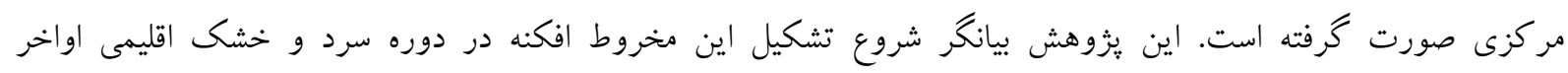

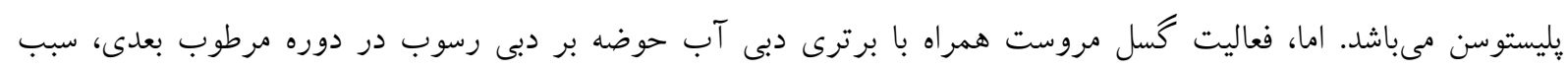

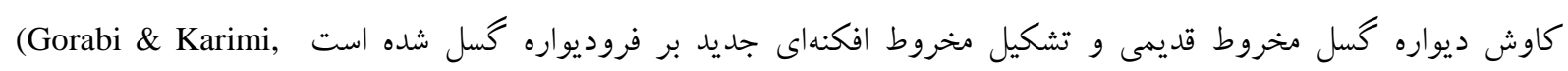

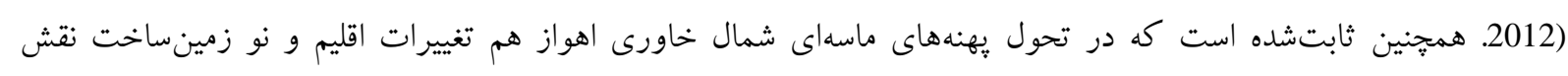

داشتهاند (Maghsoudi, Ahmadi, \& Shayan, 2016).

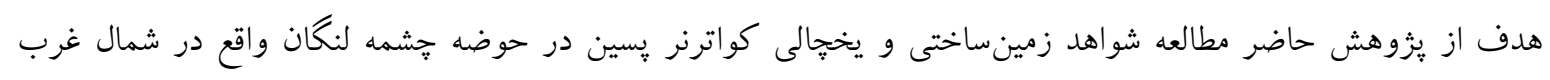

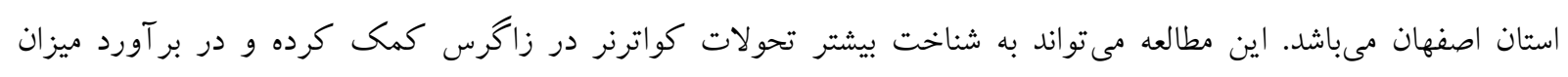
احتمال وقوع مخاطرات طبيعى در منطقه مؤثر باشد.

معرفى منطقه موردمطالعه

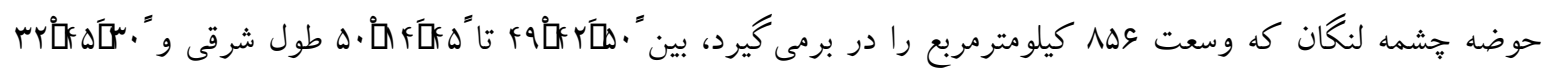

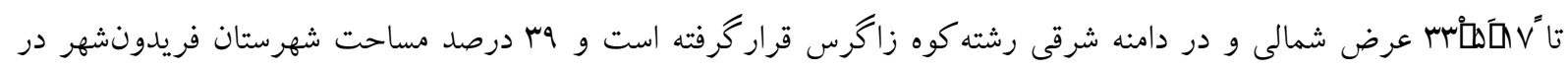

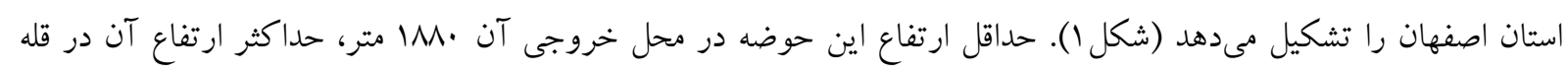

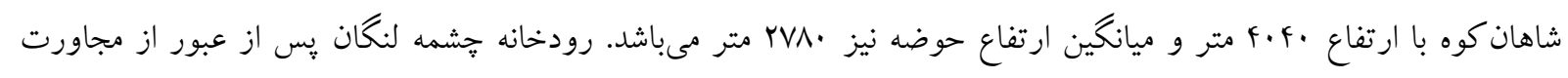

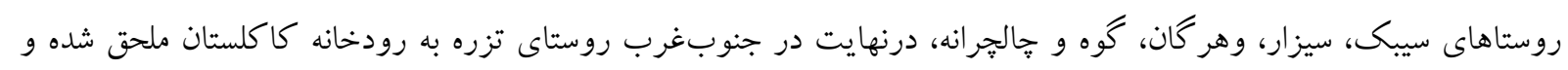

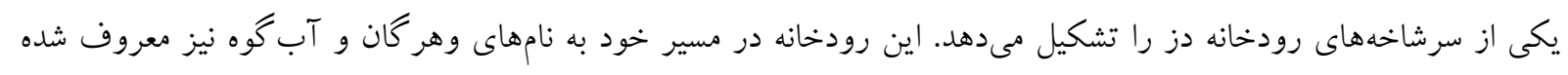

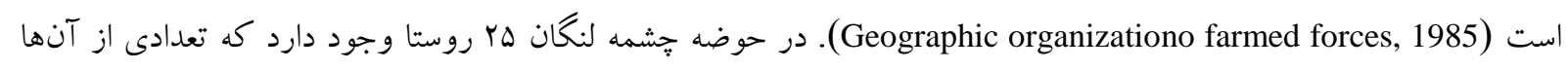

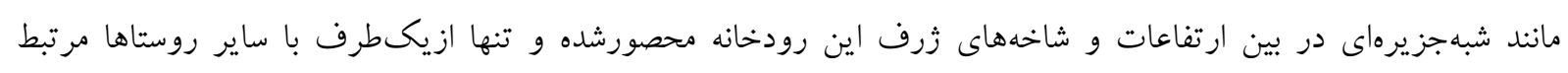

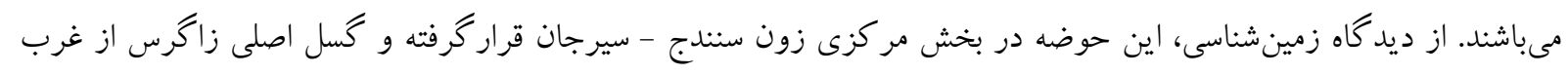

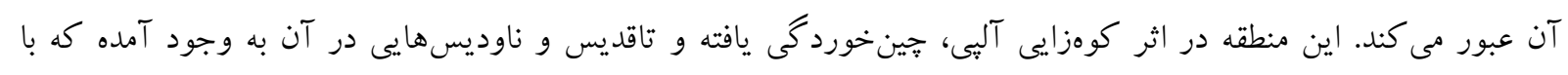

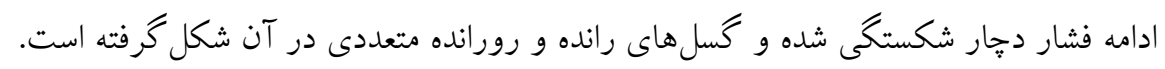




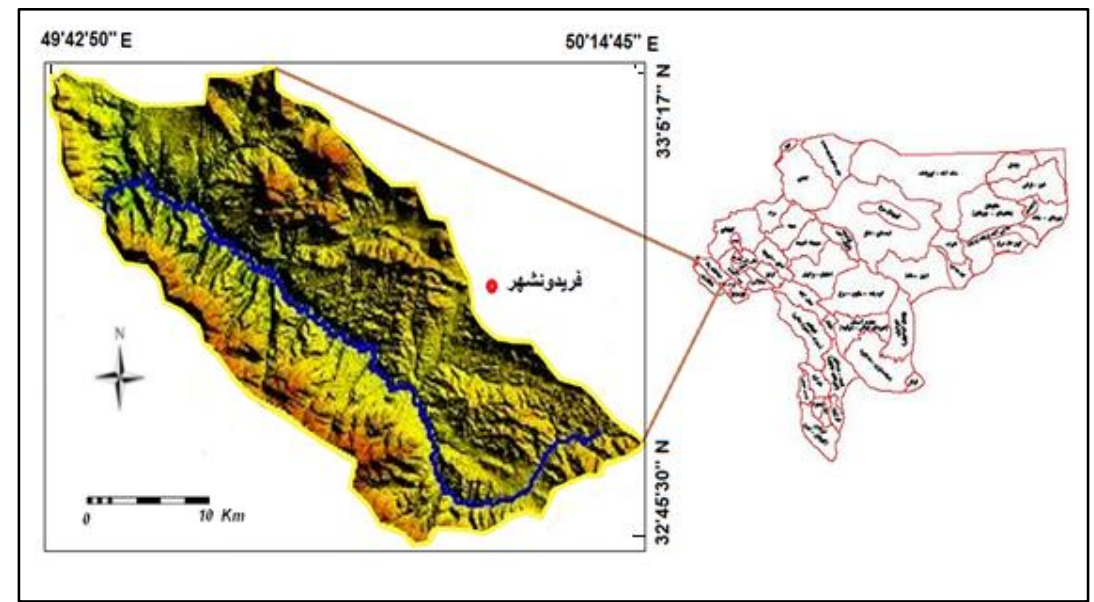

شكل 1- موقعيت جغرافيايى حوضه جشمه لنكان اصفهان

\section{روش تحقيق}

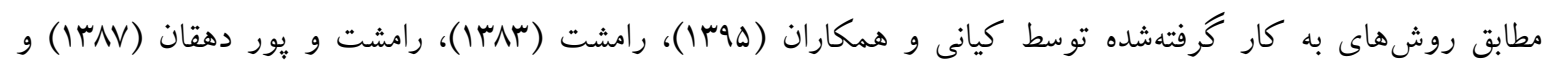

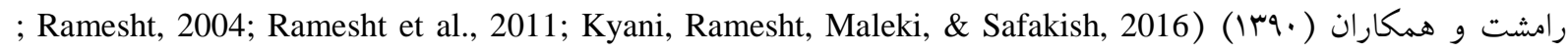
به جمع آورى آمار ايستكاههاى سينويتيك و كليماتولوزى منطقه و اطراف آن مبادرت

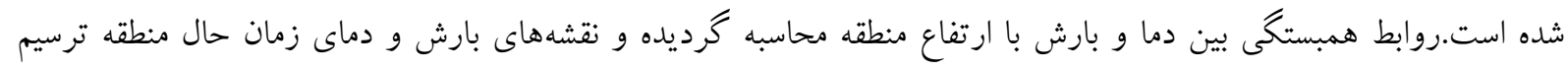

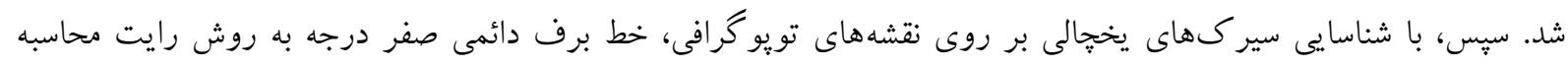

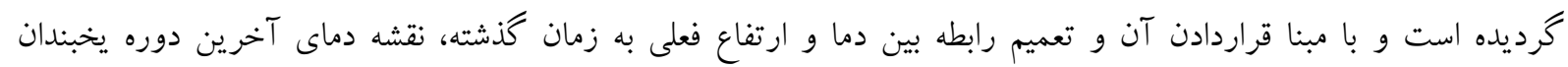

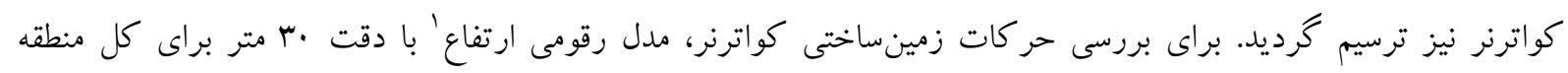

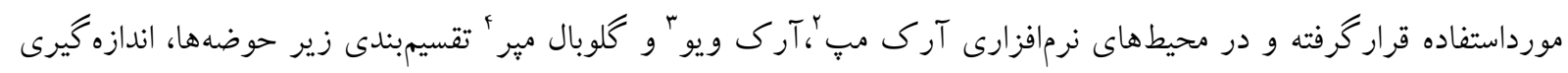

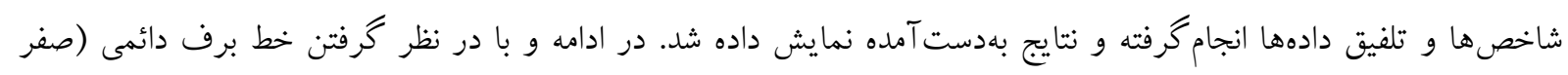

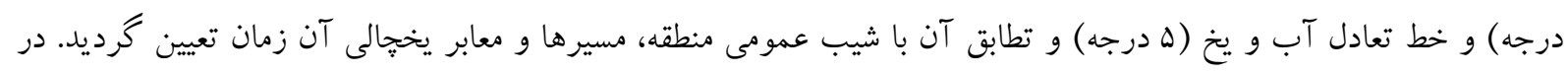

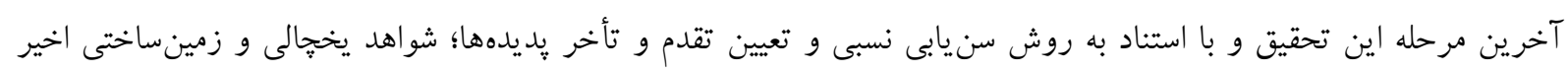

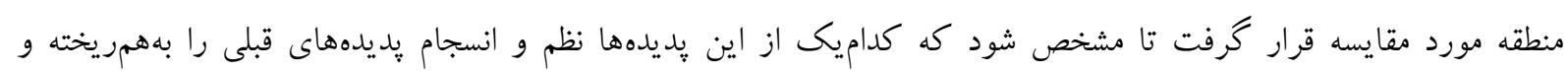
بنابراين، جديدتر بوده است.

\section{يافته هاى تحقيق}

مطابق مطالب مطرحشده درروش تحقيق، نتايج اين :ثزوهش در دو مبحث ارائهده است:

\section{الف: شو اهد يخجالى}

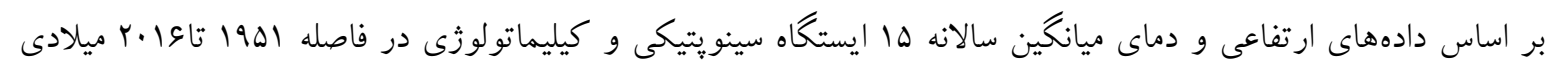

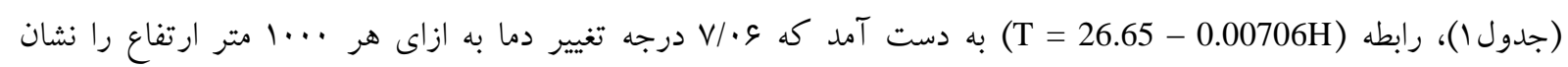

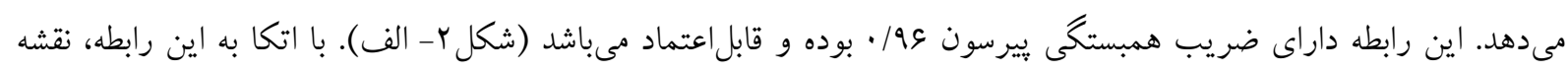




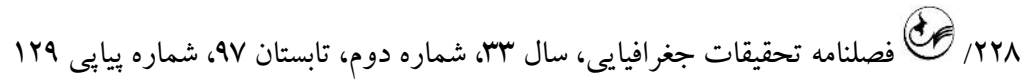
دماى فعلى حوضه ترسيم گرديد (شكل r- الف) و دماى سالانه كمينه، متوسط و بيشينه حوضه به ترتيب l/AV TH/TF

جدول 1- مشخصات ايستعاههاى سينو يتيكى و كليماتولوزى مورداستفاده.

\begin{tabular}{|c|c|c|c|c|c|c|}
\hline بارش & دما & ارتفاع & عرض جغرافيايى & طول جغرافيايى & ايستگاه & رديف \\
\hline Ira & $\mid s / r$ & $100 \cdot / F$ & ' & $01^{\circ} G \varepsilon^{\prime}$ & اصفهان & 1 \\
\hline rr. & $1 . / 9$ & rrq. & $r r^{\circ} q \varepsilon^{\prime}$ & $0 \cdot{ }^{\circ} r \varepsilon^{\prime}$ & داران & r \\
\hline$r V T / V$ & $\mid F / T$ & $1 \wedge V$ & ' & $a \cdot{ }^{\circ} I V^{\prime}$ & كليايگڤان & r \\
\hline $\mid s r / V$ & $\mid r / r$ & 191. & ' & $01^{\circ} \mid g^{\prime}$ & ميمه & f \\
\hline$\| r / \Lambda$ & $\mid Q / f$ & IDFO & MY DI' & $\Delta 1^{\circ} \wedge \Delta^{\prime}$ & كبوتر آباد & $\Delta$ \\
\hline$|r v /|$ & $19 /$ & $\mid r \Delta r / F$ & ' & $\Delta Y^{\circ} M \Lambda^{\prime}$ & اردستان & $\varepsilon$ \\
\hline HYI/A & $11 / \mathrm{V}$ & $r \cdot F N / q$ & $M Y^{\circ} Y \Lambda^{\prime}$ & $\Delta \cdot{ }^{\circ} \wedge \Delta^{\prime}$ & شهر كرد & v \\
\hline$r D F / \Gamma$ & $1 \cdot / \mathrm{V}$ & Trs. & $M^{\circ} 9 \Lambda^{\prime}$ & $\Delta 1^{\circ} \mu \cdot{ }^{\prime}$ & بروجن & $\wedge$ \\
\hline Irs & $19 / 1$ & $q \wedge r / r$ & ' ه ه & $011^{\circ} r V^{\prime}$ & كاشان & 9 \\
\hline$F \cdot 1 / s$ & $\mid r / f$ & $r \cdot r r$ & ' & $F 9^{\circ} F Y^{\prime}$ & اليكودرز & 1. \\
\hline$F \Delta S / T$ & $\mid r / F$ & $|\wedge V| / q$ & ' & $F Q^{\circ} r D^{\prime}$ & 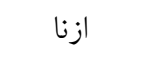 & 11 \\
\hline $190 / \Gamma$ & $10 / 0$ & $18 \wedge F / 9$ & 'به مس & $01^{\circ} \cdot 9^{\prime}$ & نطنز & Ir \\
\hline$F \Delta \Lambda / \Delta$ & $1 \mathrm{~F} / \mathrm{V}$ & lerg & 'م مس مس & $F \Lambda^{\circ} F Q^{\prime}$ & بروجرد & ir \\
\hline $\mid \Lambda F / F$ & $\mid s / 1$ & IEYY & 'به مسر & $D \cdot{ }^{\circ} r q^{\prime}$ & محلات & If \\
\hline MFV/q & if & 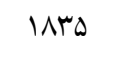 & ' ק סח & $a \cdot{ }^{\circ} \cdot \Delta^{\prime}$ & خمين & 10 \\
\hline
\end{tabular}

منبع: سازمان هو اشناسى كشور

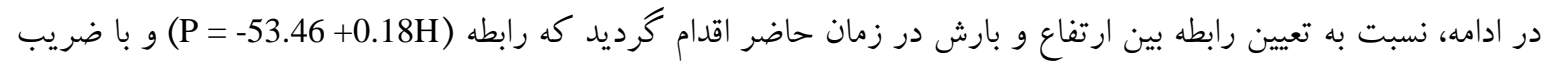

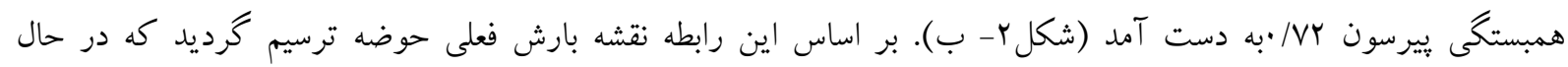

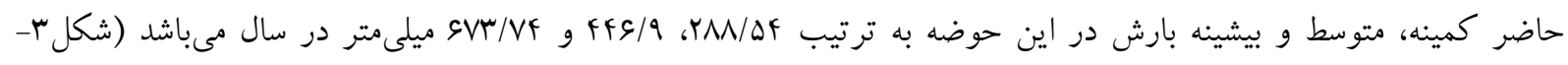
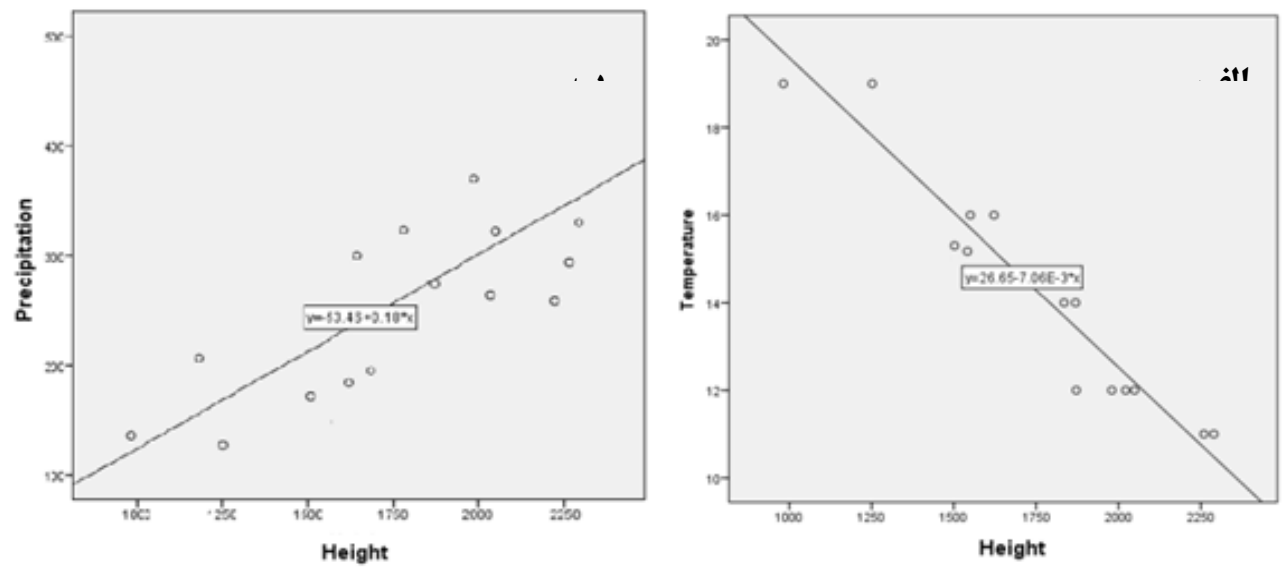

شكل r - رابطه بين عناصر اقليمى؛ الف) نمودار ارتفاع - دما، ب) نمودار ارتفاع - بارش 


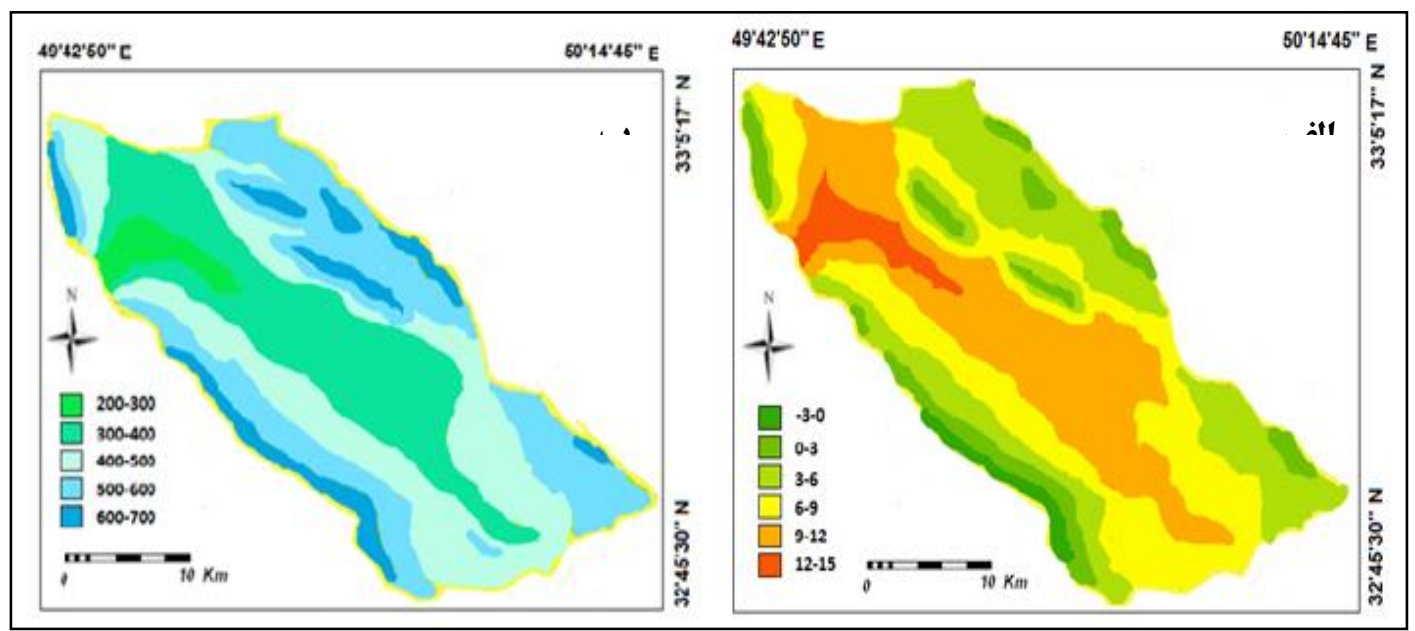

شكل r- نقشه هاى اقليمى فعلى منطقه؛ الف) دما، ب) بارش

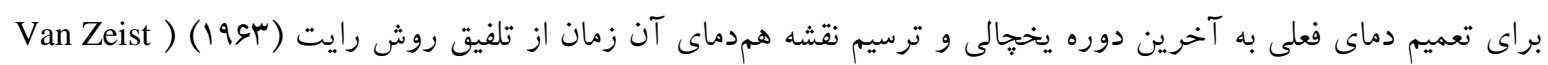

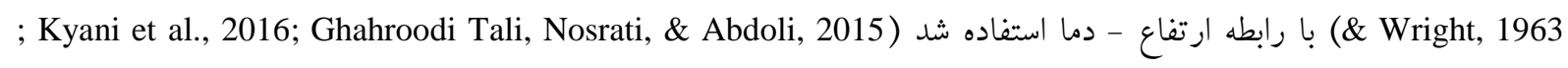

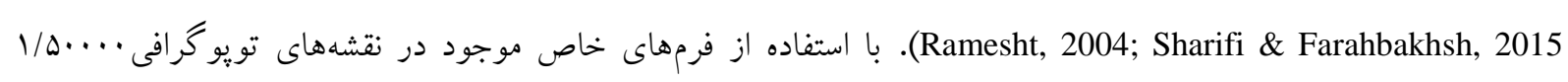

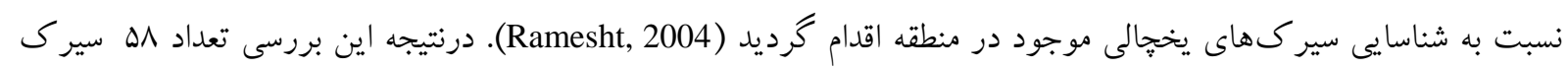

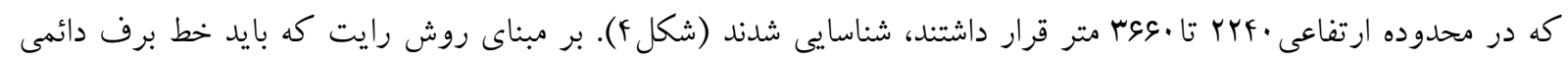

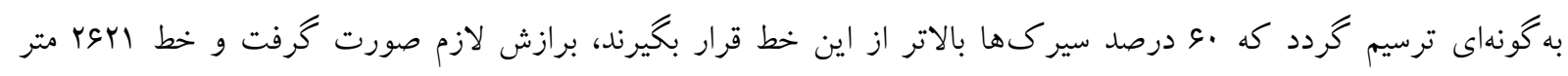

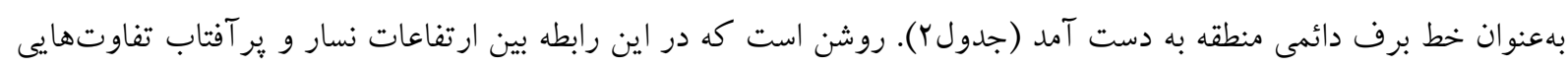

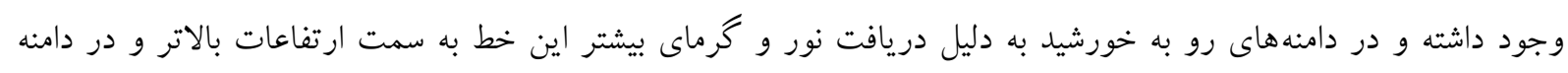

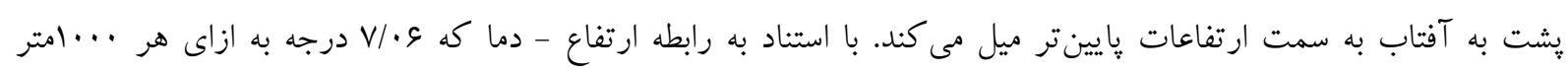

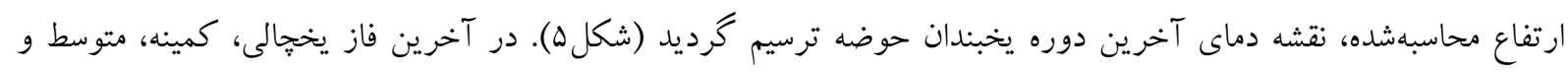

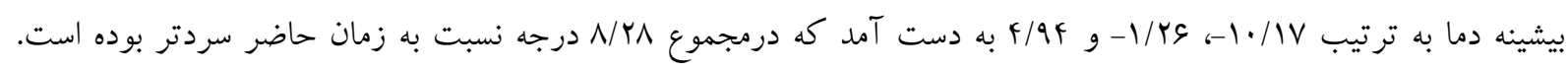

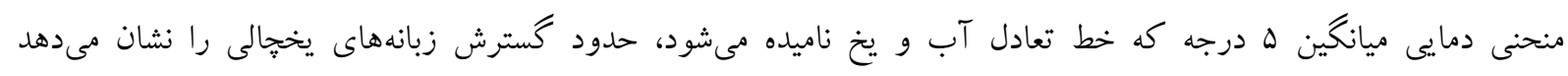
(Ramesht \& Kazemi, 2007) بوده و ارتفاع آن در دامنهاى نسار و برآنتاب تفاوت مى كند.

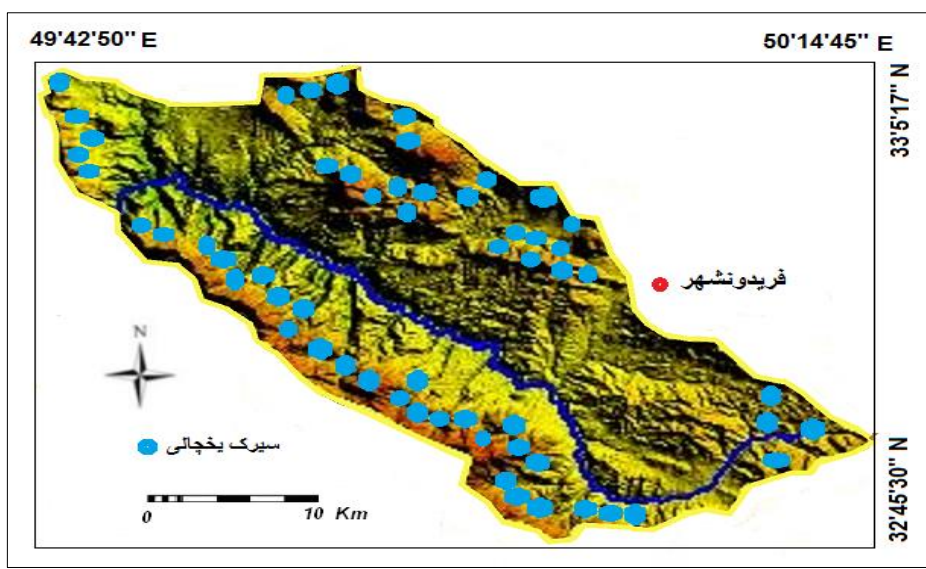

شكلع- موقعيت سير كتهاى يخجالى در حوضه جشمه لنكان اصفهان 


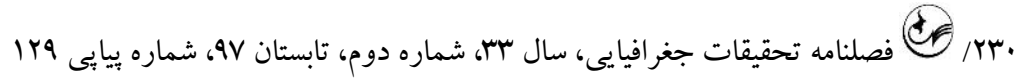
جدول r- رابطه بين ارتفاع و تعداد سير كهاى يخجالى جهت تعيين خط برف دائمى

\begin{tabular}{|c|c|c|c|c|c|c|c|c|c|}
\hline 9 & $\wedge$ & V & $\varepsilon$ & $\Delta$ & f & $r$ & r & 1 & رديف \\
\hline 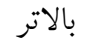 & $-M F .$. & $-M_{T} . \cdot$ & $-r \ldots$ & $-r \wedge .$. & $-r \varepsilon .$. & $-Y F \cdot$. & $-Y r .$. & كمتر از & \multirow{2}{*}{ ارتفاع } \\
\hline از از.. & rs.. & MF.. & Mr.. & $\mu \ldots$ & 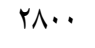 & rs.. & YF.. & $r r .$. & \\
\hline 1 & $r$ & r & $r$ & V & $r$. & 11 & F & · & تعداد سيركى \\
\hline r & $\Delta$ & r & $\Delta$ & Ir & $M F / D$ & MI & $8 / 9$ & · & درصد مطلق \\
\hline \multirow[t]{2}{*}{$99 / 4$} & $9 V / f$ & $9 r / 4$ & $\wedge q / f$ & $\Lambda F / f$ & $V Y / F$ & $\mathrm{rV} / \mathrm{q}$ & $8 / 9$ & $\cdot$ & درصد تجمعى \\
\hline & & $\%$. & & & YEYI & & $\%$. & & خط برف دائمى \\
\hline
\end{tabular}

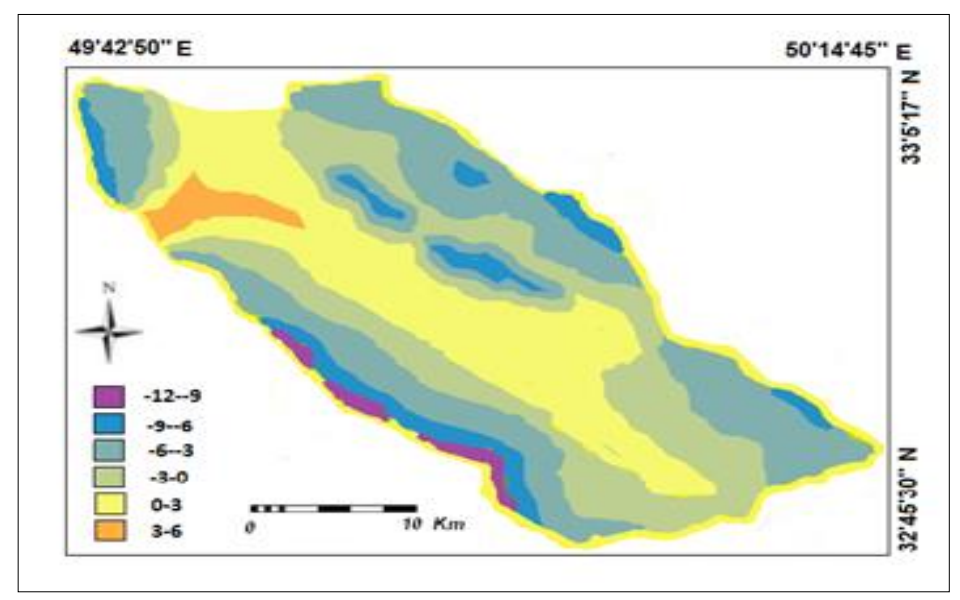

شكل 0- نقشه دماى آخرين دوره يخبندان كواترنز

بنابراين، نتيجه كيرى مىشود كه VT درصد از منطقه بالاتر از خط برف دائمى قرار داشته و دائماً يوشيده از برف و يخ بوده دون

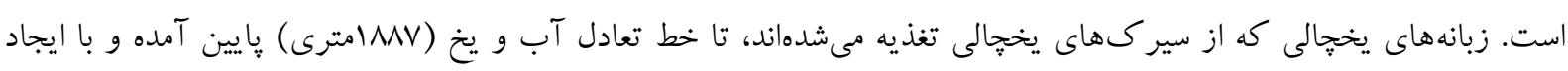
درههاى U شكل، در امتداد شيب عمومى منطقه به سمت شمال غرب حركت كرده و از حوضه موردبحث خارج مىشدهاند. رسوبات يخجالى شامل مورنهاى يخجالى ' و رسوبات آبرفتى است كه در اثر عملكرد يخجالها به وجود مى آيند. اين رسوبات عموماً فاقد نظم دانهاى بوده و كانىهاى فرسايش نيافته، زاويهدار و مخطط در آنها به فراوانى يافت مىشود. انديس فرسايش كوخى، انديس طويل شدكى زياد و منحنى گرانولومترى نامتجانس از مشخصات بارز آنهاست. در حوضه جشمه لنگان اين نوع رسوبات بهصورت يراكنده مشاهده مىشوند و فرمهاى كلاسيك يخجالى نيز بهندرت در ميان آنها يافت مى شود (شكل ع). همانطور كه در ادامه مقاله به آن اشاره خواهد شد، دليل آن اين است كه بخش زيادى از رسوبات كه در داخل منطقه برجاىماندهاند، در اثر وقوع گسل خورد گى و فرسايش شديد متعاقب آن از منطقه خارجشدهاند. 


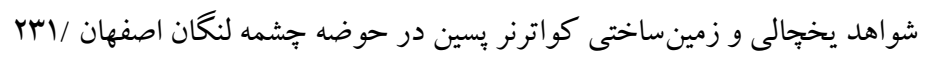

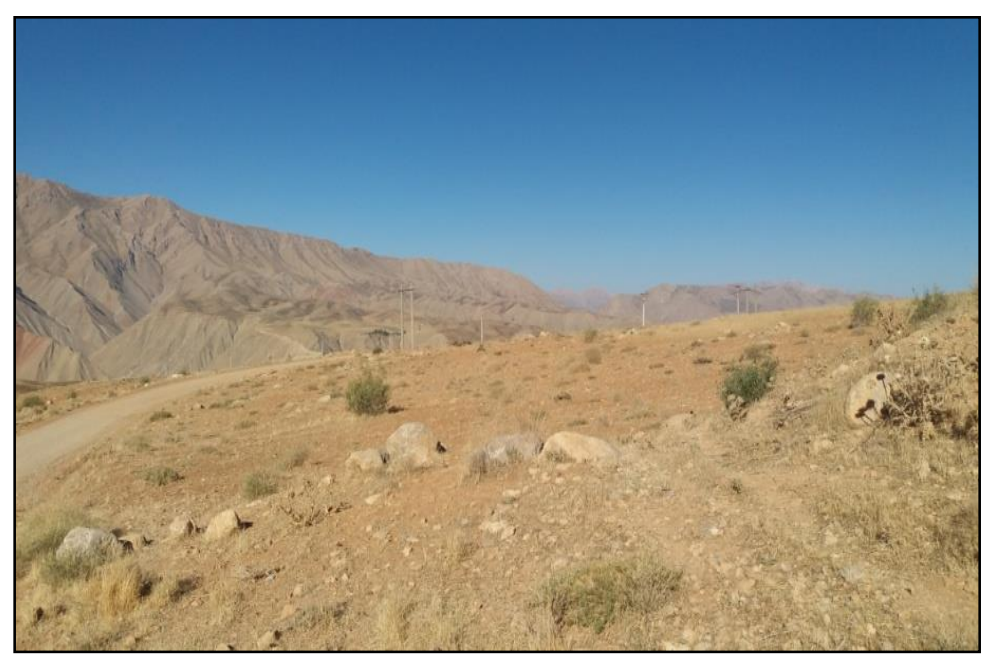

شكل 7- رسوبات يخجالى يراكنده در شمال روستاى سيزار

$$
\text { ب: شو اهد زمين ساخت فعال }
$$

اين حوضه به ع زير حوضه شاهبلاغ، تنگ دوزدان، دربند، سيبك، سرداب و خرمدره تقسيمشه و شاخصهاى زمينساخت

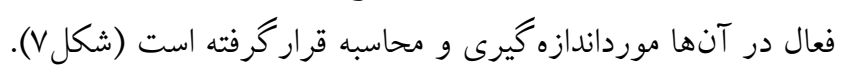

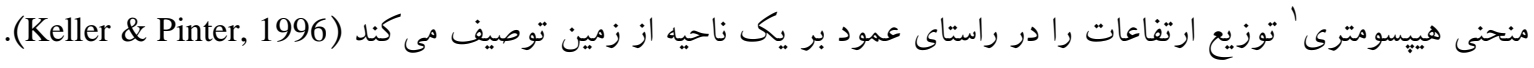

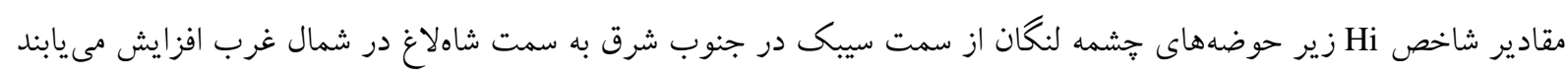

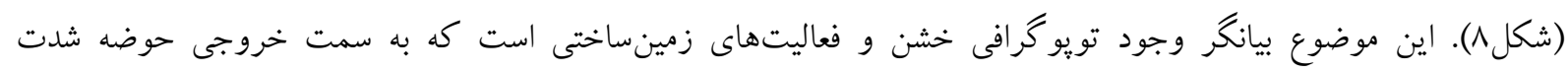

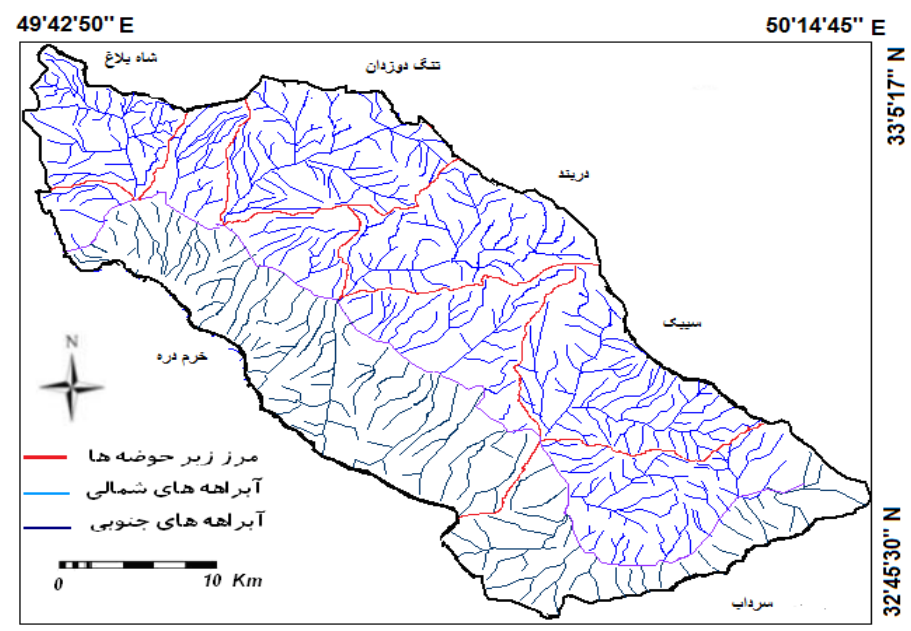

شكل Y- تقسيمبندى زير حوضهها 


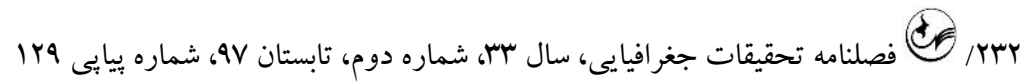

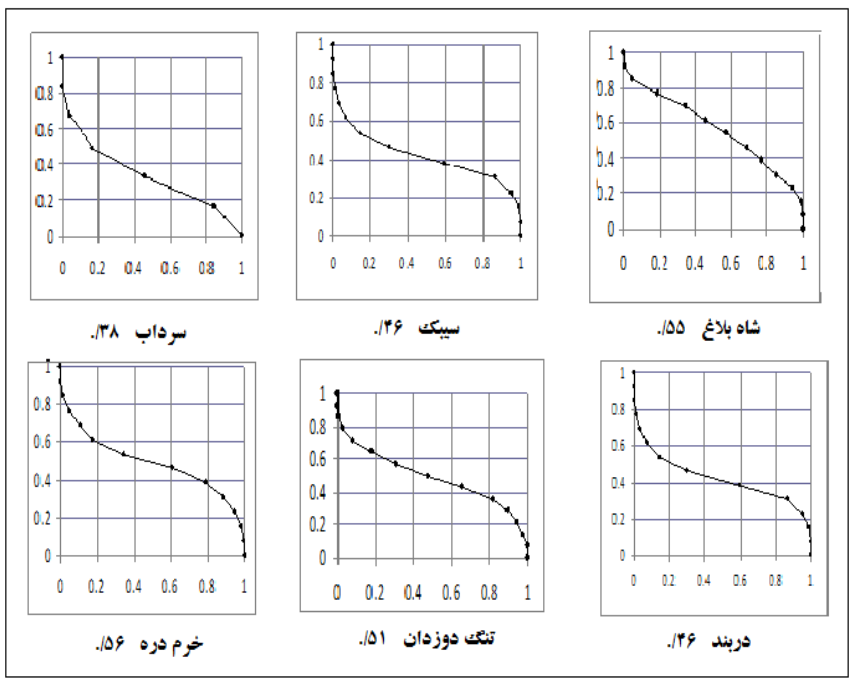

شكل^- منحنى هييسومترى زير حوضه هاى جشمه لنغان

- شاخص SL ارتباط طول - كراديان رود را نشان مىدهد كه مقادير زياد آن نشانه فرايش و يا يايين رفتن سطح اساس منطقه مىباشد (Hack, 1973). اين شاخص براى رودخانهاى سرداب، سيبك، دربند، تنگ دوزدان، شاهبلاغ و خرمدره به ترتيب اعداد FFV، FA تعادل به سمت خروجى منطقه مىباشد. تاثير گسل زاكرس را بر نيمرخ رودخانه شاهبلاغ در شكل 9 مشهود است. - هر كاه مقدار شاخص ييج و خم رودخانه (S) كاهش يابد و به عدد انزديك شود، بيانكر افزايش فعاليت تكتونيكى منطقه

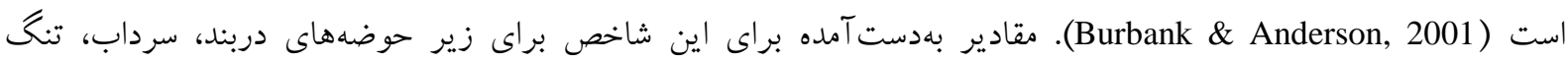

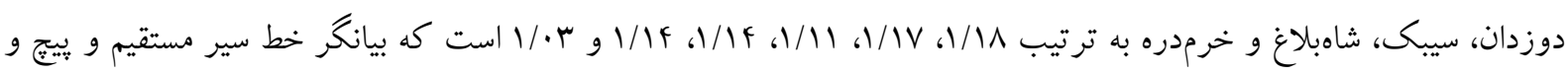
خم كم رودخانه ها در مسيرهاى منتهى به خروجى حوضه مىباشد.

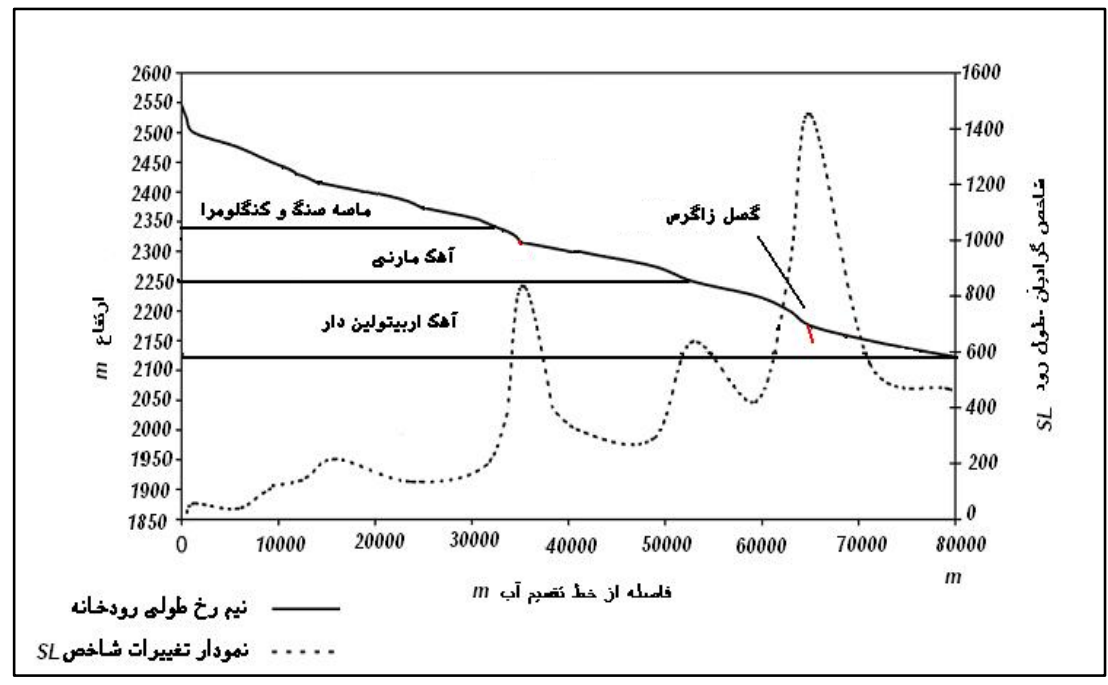

شكل q- تأثير كسل زاترس بر كراديان شيب رودخانه شاهبلاغ

- رودها در هاسخ به حر كات زمينساختى فعال ابتدا بستر خود را حفر مى كنند كه شدت اين عمل با تعديل مجدد گراديان رودخانه و رسيدن به سطح اساس جديد كم شده، عقبنشينى شيبهاى طرفين دره رودخانه شروع مىشود. شاخص Vf نسبت 
عرض كف دره به ارتفاع آن را مىسنجد (Bull, 2007). اين شاخص براى زيرحوضههاى شاهبلاغ، سيبك، سرداب، دربند، تنگ

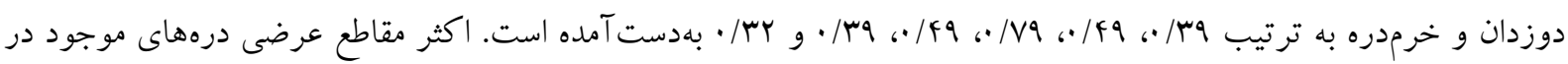

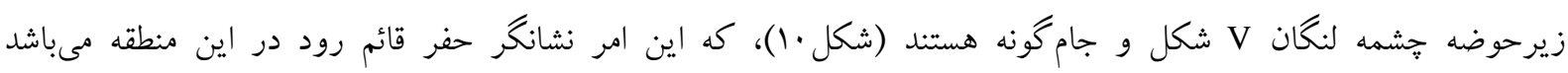

.(Soleimani, 1999)

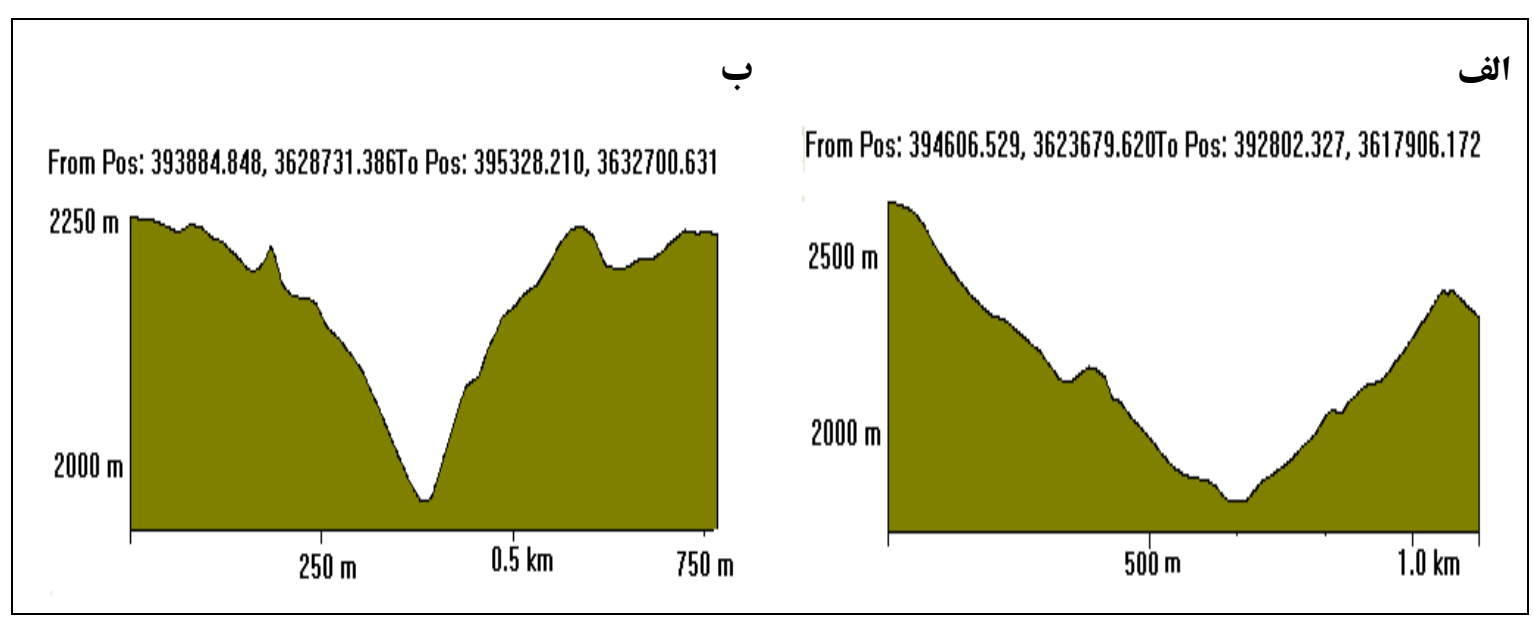

شكل • ا - نمونههايى از نيمرخهاى عرضى درههاى موجود در منطقه؛ الف: دره سيبك، ب: خرمدره

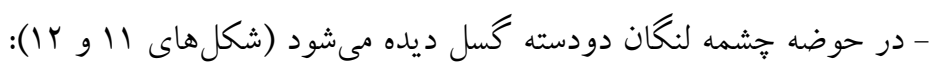

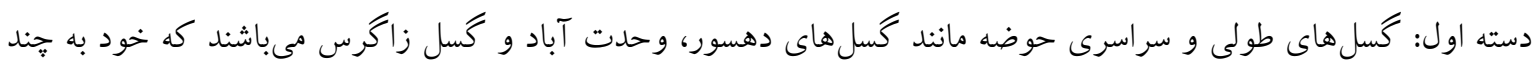

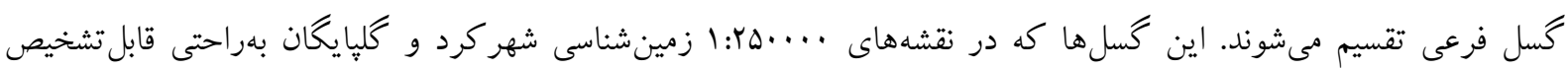

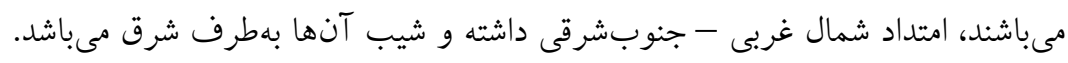

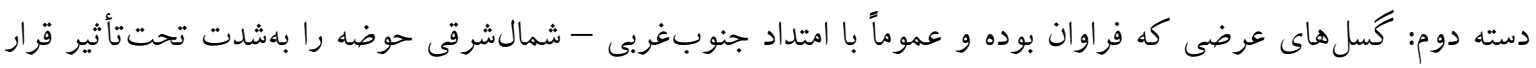

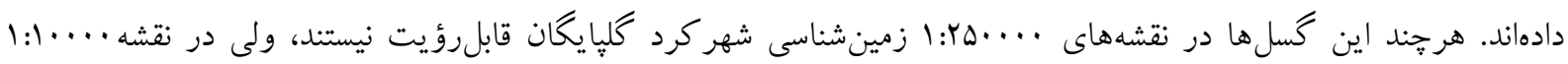
زمين شناسى اليكودرز و همجنين عكس هاى ماهو ارهاى مشخص مى باشند.

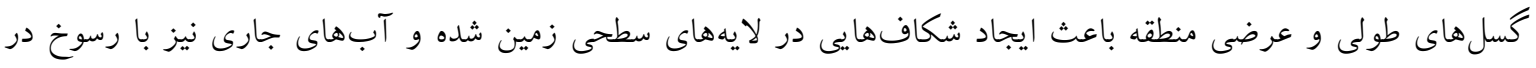

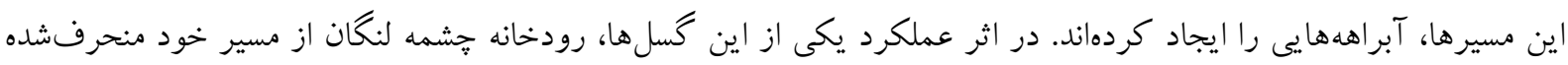

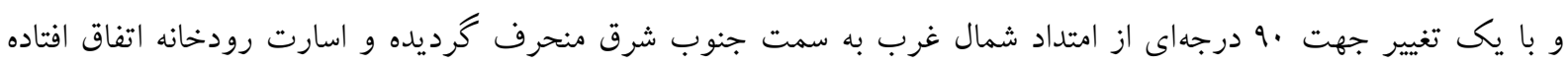
است (شكل (1)).

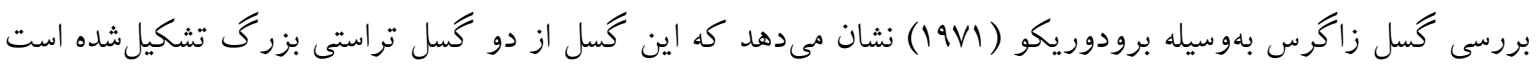

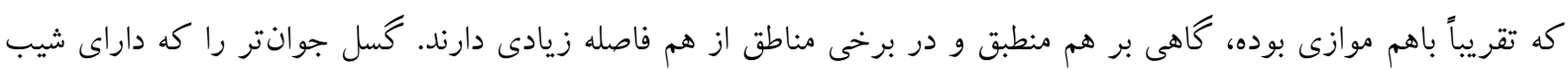

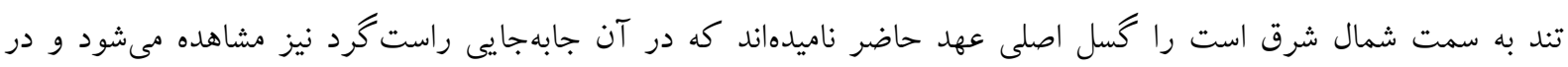

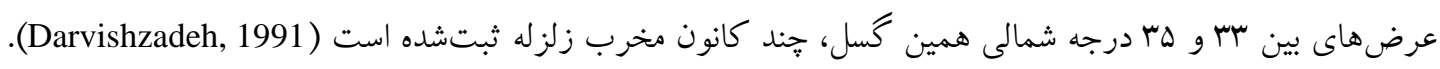

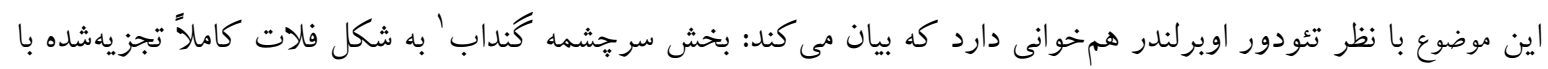

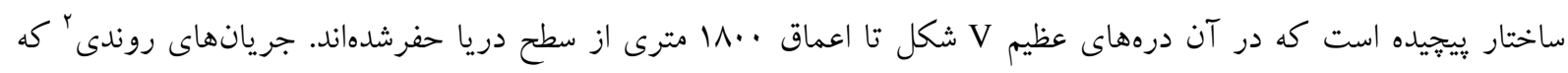




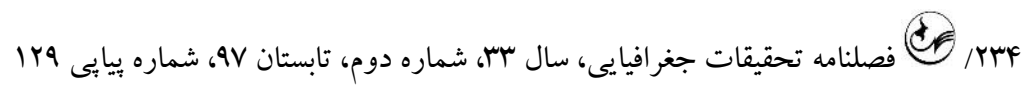
بهطور گسترده توسعه يافتهاند، در امتداد محل تماس زمينشناسى كه و درواقع گسلهاى طولانى مىباشند، جريان دارند. وى

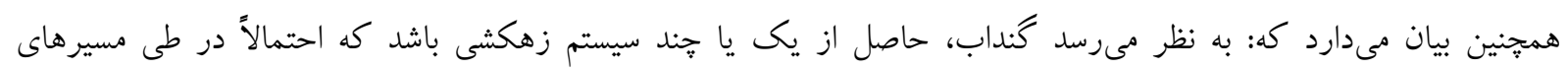
طولانى به سمت شمال غرب يا جنوب شرق به نحوى به خليجفارس راه داشتهاند (Oberlender, 2000).

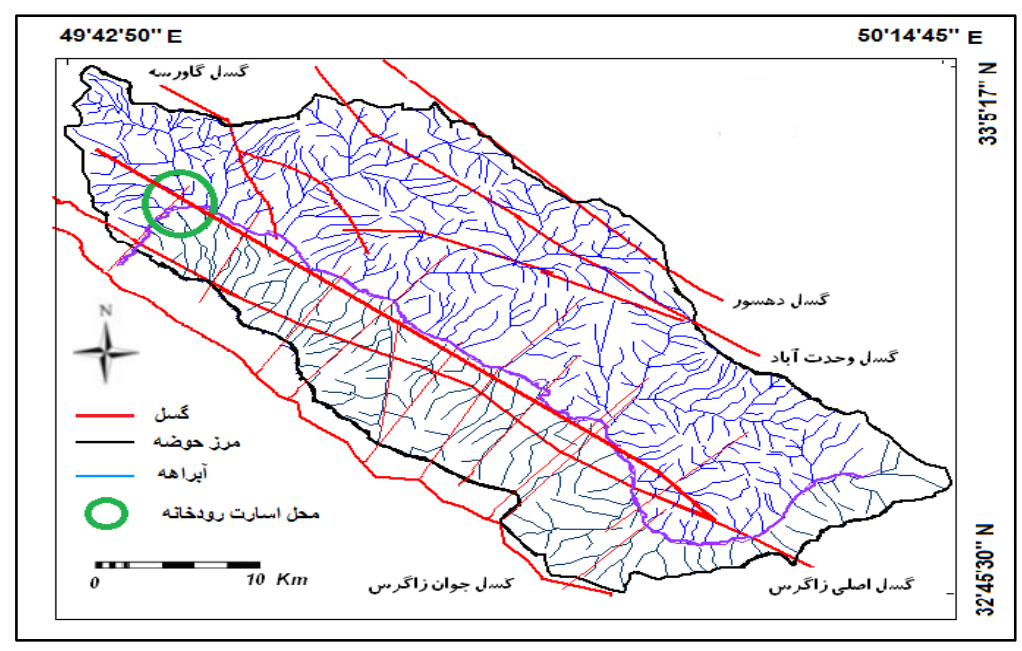

شكل 11 - كسلهاى طولى و عرضى حوضه جشمه لنغان

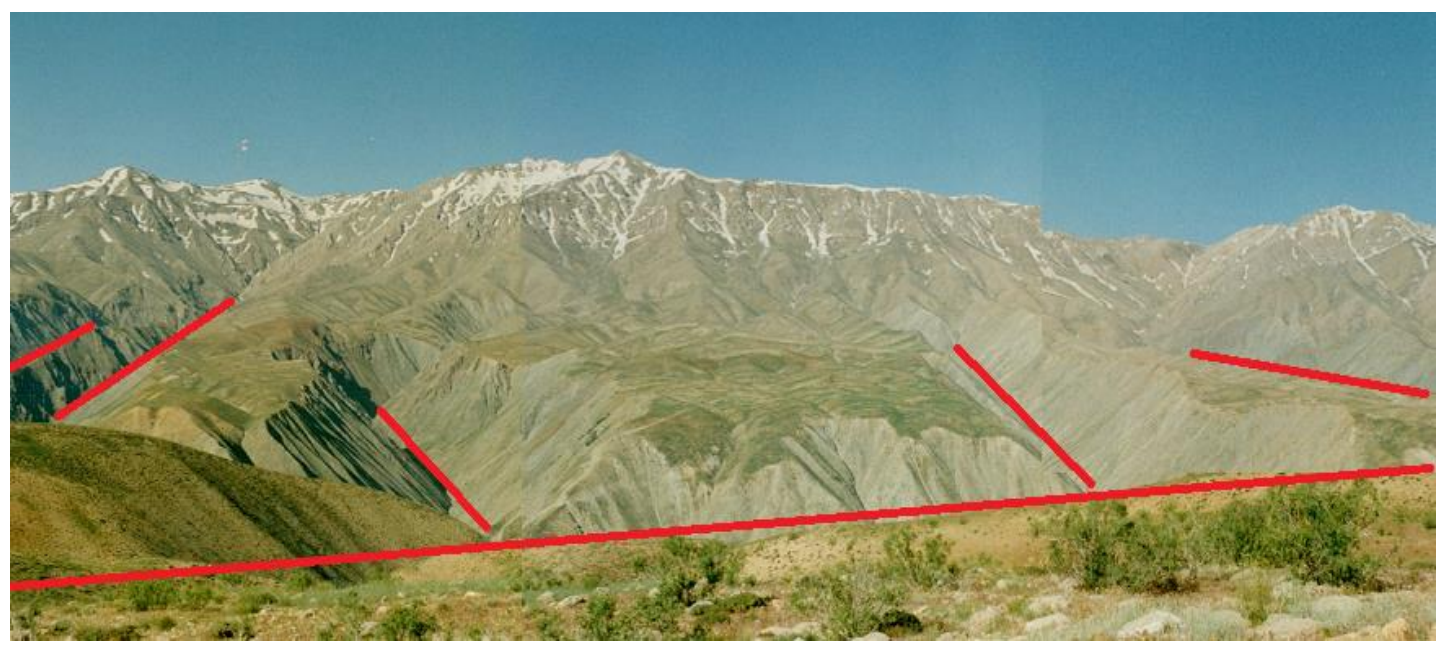

شكل r| - درههاى طولى و عرضى در امتداد كسلهاى موجود در منطقه (ديد به سمت جنوب غربى حوضه)

نتيجه گيرى

طبق شواهد بهدست آمده در اين تحقيق، در آخرين مرحله يخبندان كواترنر حدود Vr درصد از منطقه دائماً يوشيده از يخ و

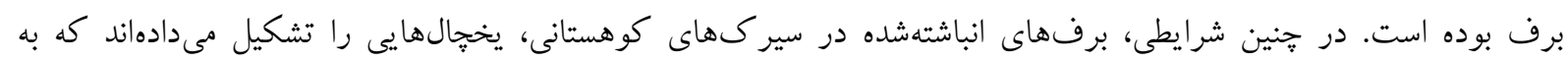

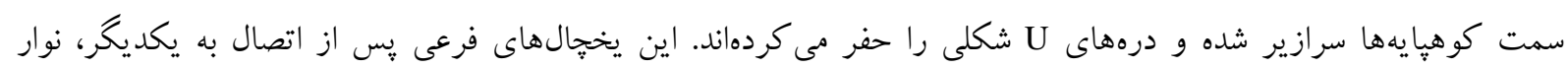

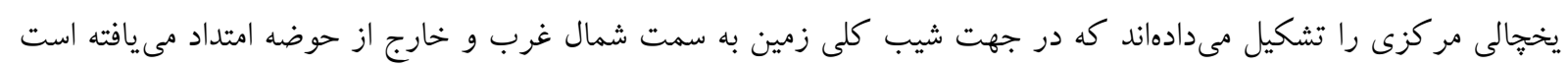

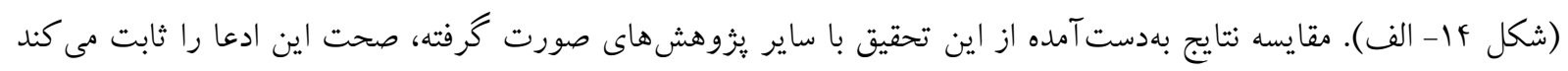


شواهد يخجالى و زمين ساختى كواترنر يسين در حوضه جشمه لنكان اصفهان /WTH

جدول ץ- مقايسه دادههاى حاصل از جند يُزوهش در مورد يخجال های كوهستانى ايران

\begin{tabular}{|c|c|c|c|c|c|c|}
\hline \multirow[b]{2}{*}{ 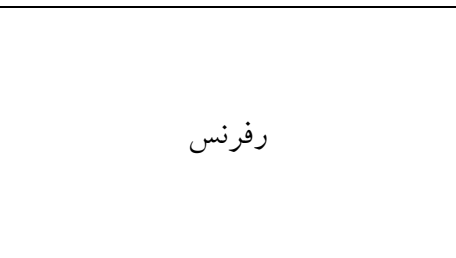 } & \multicolumn{4}{|c|}{ آخرين مرحله يخبندان كواترنر } & \multirow[b]{2}{*}{ نام منطقه موردمطالعه } & \multirow[b]{2}{*}{ رديف } \\
\hline & 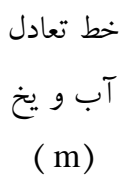 & $\begin{array}{l}\text { خط برف } \\
\text { دائمى } \\
\text { (m) }\end{array}$ & 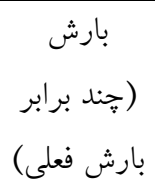 & $\begin{array}{c}\text { (سردتر از } 2 \text { دماى فعلى) } \\
\text { (سلى }\end{array}$ & & \\
\hline (مقاله حاضر) & IAWV & TEYT & - & N/TA & حشمه لنكان اصفهان & 1 \\
\hline (Ramesht, 2004) & rl.. & rsA. & $1 / 1$ & 9 & زفره اصفهان & r \\
\hline (Almodaresi \& Ramesht, 2007) & rma. & rrr. & $1 / 4$ & $\wedge$ & سخويد يزد & $r$ \\
\hline (Rafiei, 2009) & lar. & reVY & $1 / \Delta$ & 9 & كهى قم & i \\
\hline (Ghahroodi Tali et al., 2015) & - & rAr. & - & $\Delta / \Gamma \Lambda$ & دالاخانى كرمانشاه & $\Delta$ \\
\hline (Ramesht et al., 2011) & $19 .$. & $r q .$. & I/rT & $\Lambda / \Delta$ & تير كانى ماهان & s \\
\hline
\end{tabular}

با بررسى شاخص هاى مختلف معرف زمينساخت يويا و كسلهاى منطقه اين واقعيت آشكار شد كه يس از آنهان آخرين دوره

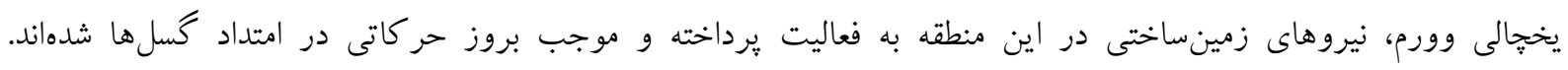

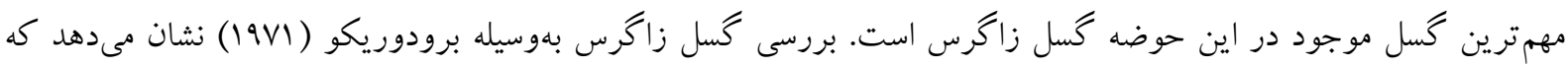

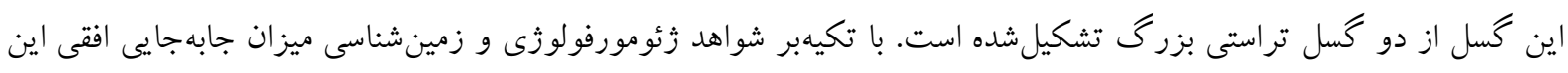

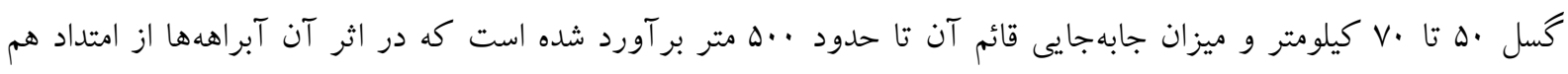

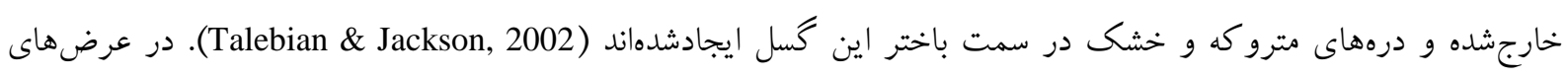

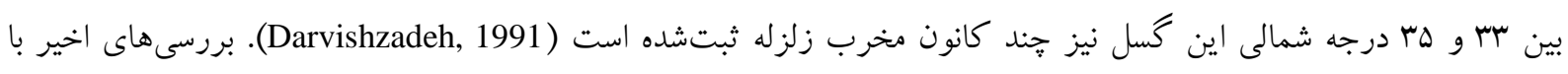

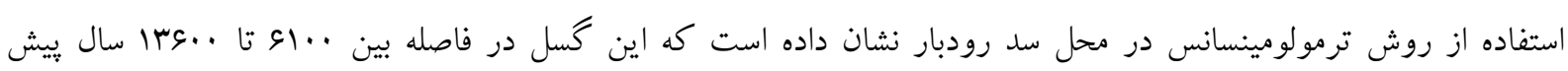
جنبا بوده است (Samari, Mojtahedi, Soroush, \& Heidari, 2005).

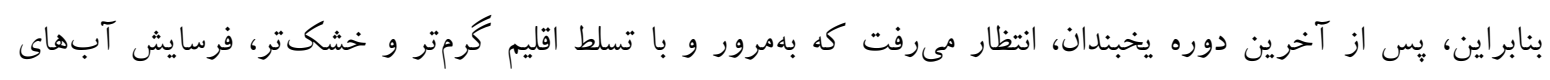

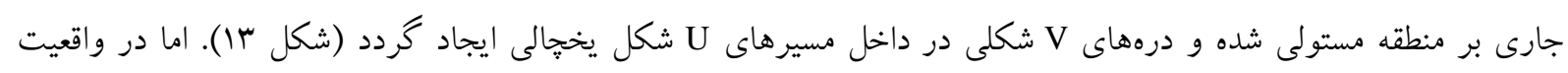

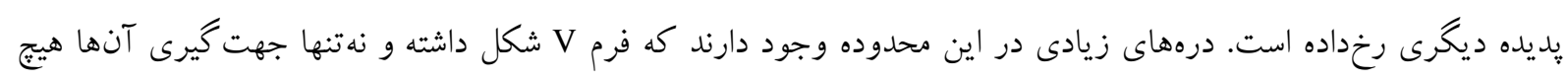

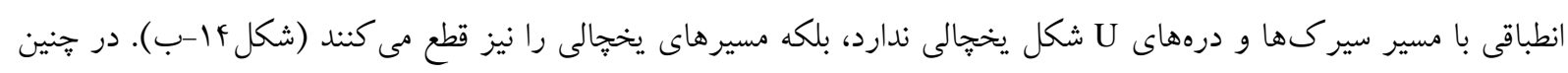

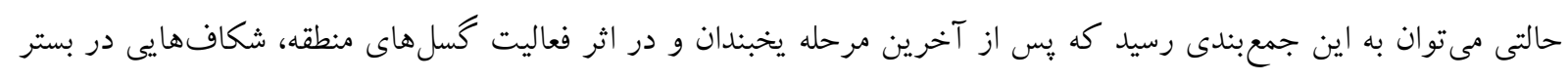

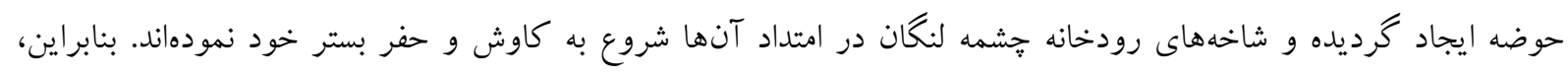

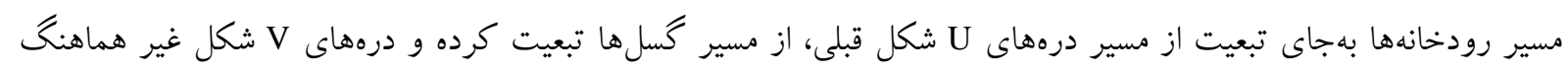

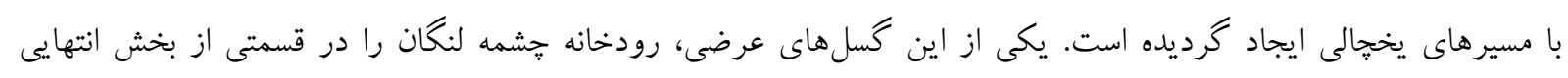

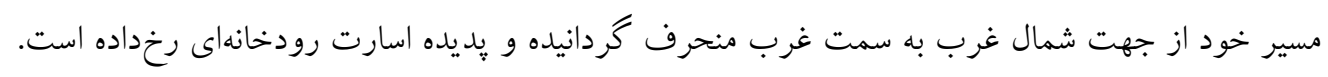




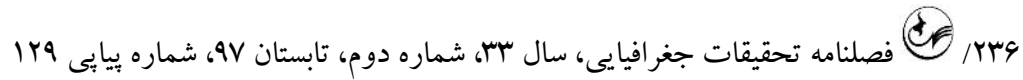

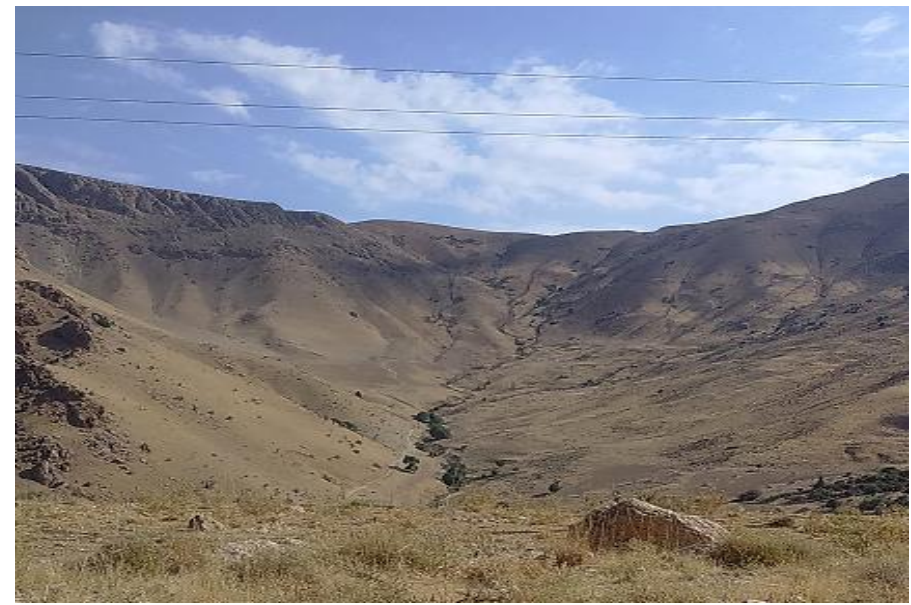

شكل سا 1 - سير كى يخجالى جقيورت

كه تحت تأثير حر كات زمينساختى جديد قرار نكرفته است

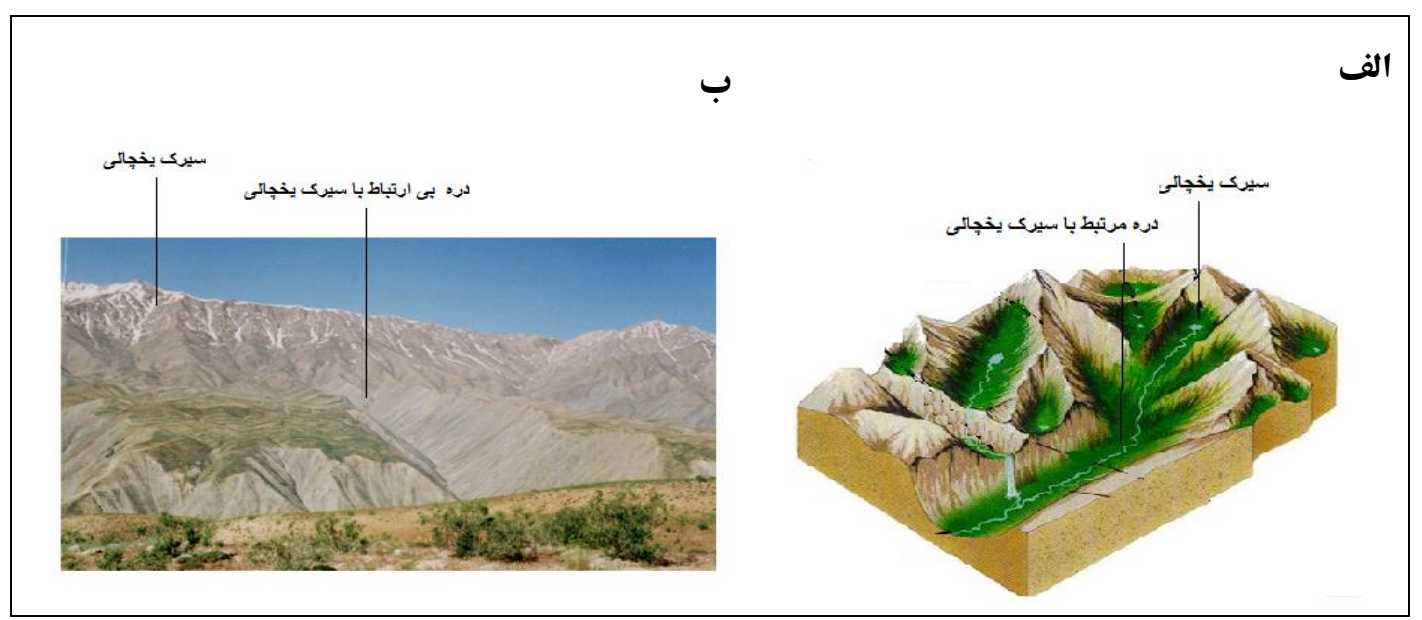

شكل عا - انواع درهها؛ الف - درههاى يخجالى، ب- درههاى زمينساختى

در حال حاضر حوضه جشمه لنگان به يك فلات تجزيهشده تبديلشده است كه در مرحله تجديد جوانى قراركرفته و

فرسايش بالايى در آن حكمفرما مىباشد. با توجه به اين سوابق، امكان فعاليتهاى زمينساختى جديد نيز در اين حوضه وجود

براى تهيه اين مقاله از راهنمايىهاى جناب آقاى دكتر محمدحسين رامشت استاد كروه جغرافياى دانشخاه اصفهان برخوردار

$$
\text { شدم كه لازم مىدانم از ايشان تشكر و قدردانى نمايم. }
$$

\section{منابع و مآخذ}

Almodaresi, S. A., \& Ramesht, M. (2007). The glacial effect of Shirkooh Yazd in sokhvid region. Geographic Space, 19, 1-32. (Persian)

Bayati Khatibi, M. (2009). Diagnosis of neotectonic activities in the Cornucchia basin using morphotectonic and geomorphologic indicators. Geographic Space Magazine, 9(25), 23-50. (Persian).

Bull, W. B. (2007). Tectonic geomorphology of mountains :A new approach to paleoseismology. Malden:

Wiley-Blackwell. [DOI:10.1002/9780470692318]

Burbank, D. W., \& Anderson, R. S. (2001). Tectonic geomorphology. England: Backwell.

Darvishzadeh, A. (1991). Iranian geology (First ed.). Tehran: Nasdanash Publications. (Persian) 
Geographic Organization of Armed Forces. (1985). Topographic maps, 1/50000 and 1/25000 Shahrekord and Golpayegan. (Persian)

Ghahroodi Tali, M., Nosrati, K., \& Abdoli, I. (2015). Estimate of snow-line in the past glacial in Dalakhani basin. Geography and Environmental Planning Journal, 26(2), 231-246. (Persian)

Gorabi, A., \& Karimi, M. (2012). The effect of active tectonics and climate change on the evolution of the convection of Marvette, Central Iran. Journal of Applied Geosciences Research, 12(27), 7-30. (Persian)

Hack, J. T. (1973). Stream-profile analysis and stream-gradient index. Journal of Research of the US Geological Survey, 1(4), 421-429.

Hussein Khan Nazer, N. (2015). Quaternary Geology (First ed.). Tehran: Geological Survey and Mineral Exploration. (Persian)

Jedari Eyvazi, J. (2008). Geomorphology of Iran (Fourth ed.). Tehran: Payame Noor University. (Persian)

Keller, E. A., \& Pinter, N. (1996). Active tectonics: Earthquakes, uplift and landscape. London: Prentice Hall Pub.

Kyani, T., Ramesht, M. H., Maleki, A., \& Safakish, F. (2016). Climate change in Gavkhouni basin at the late quaternary phase. Natural Geographic Research, 48(2), 213-229. (Persian)

Maghsoudi, M., Ahmadi, A., \& Shayan, S. (2016). The effect of neonate construction and climate change on the development of northwest sandwich zones of Ahwaz. Quantitative Geomorphology Researches, 5(1), 160-180. (Persian)

Mahmoodi, F. (1998). The rhetoric of Iran in quaternary. Quarterly Journal of Geographic Research, 23, 5-43. (Persian)

Motammad, A. (1998). Quaternary (First ed.). Tehran: Tehran University Press. (Persian)

Oberlender, T. (2000). Zagros rivers from geomorphology view (A. Abbasnejad, Trans. First ed.). Tabriz: Tabriz University Press. (Persian)

Radfar, S., \& Pourkermani, M. (2006). Morphotectonic of Kuhbanan fault. Geosciences, 15(58), 166-183. (Persian)

Rafiei, G. R. (2009). Throat thoughts of geology. (Master), Isfahan University, Isfahan. (Persian)

Ramesht, M. H. (2004). The works of the fourth glaciers in the suburbs of Isfahan. Journal of Growth Geography, 67, 10-21. (Persian)

Ramesht, M. H., \& Kazemi, M. M. (2007). Glacier works in the Euclid basin of Fars. Growth of Geography Education, 21(4), 3-11. (Persian)

Ramesht, M. H., Lajevardi, M., Lashkari, H., \& Mahmoodi Mohammad Abadi, T. (2011). Study of natural glacial evidences in mahan (case study: Glacier of Tigrany Mahan basin). Geography Magazine and Environmental Planning, 22(2), 59-78. (Persian)

Ramesht, M. H., \& Pourdehghan, D. (2008). Ice in the fire: Glacier works in Bam area. Geographical Survey Quarterly, 23(2), 129-144. (Persian)

Samari, H. F., Mojtahedi, A., Soroush, M., \& Heidari, A. (2005). Rudbar Lorestan dam and hydro plant: Challenging seismicity conditions. Paper presented at the Hydropower Conference, Villach, Austeria.

Shafie Bafti, A., Pourkarmani, M., Shapasandzadeh, M., \& Iranmanesh, F. (2009). Landfill and evaluation of Kuhbanan fault activity by computing geomorphic indices. Natural Geography Quarterly, 1(3), 43-57. (Persian)

Sharifi, M., \& Farahbakhsh, Z. (2015). Investigation about temperature and humidity anomalies between pleistocene and present times; Reconstruction of climate condition using geomorphic evidence (case study: Khezrabad-Yazd). Natural Geography Studies, 47(4), 583-605. (Persian)

Soleimani, S. (1999). Guidelines for identifying active and young tectonic movements with an attitude to the preconditions of paleontology: International Institute of Seismology and Earthquake Engineering. (Persian)

Tabasi, H., \& Najimi, A. (2016). Young vertical movements in the Gareh Chay basin of Markazi province. Journal of Natural Environment, 5(9), 89-106. (Persian)

Talebian, M., \& Jackson, J. (2002). Offset on the main recent fault of NW Iran and implications for the late cenozoic tectonics of the Arabia-Eurasia collision zone. Geophysical Journal International, 150(2), 422-439. [DOI:10.1046/j.1365-246X.2002.01711.x]

Van Zeist, W., \& Wright, H. E. (1963). Preliminary pollen studies at Lake Zeribar, Zagros mountains, southwestern Iran. Science, 140(3562), 65-67. [DOI:10.1126/science.140.3562.65]

Yamani, M., \& Zamani, H. (2007). Restoration of the snow vear the border of the Shahrekord valley in the last glacial period. Geography Magazine and Environmental Planning, 5(12-13), 99-116. (Persian) 